\title{
Emerging understanding of the protein corona at the nano-bio interfaces
}

Morteza Mahmoudi ${ }^{a, b^{*}}$, Nicolas Bertrand ${ }^{c}$, Harshal Zope ${ }^{a}$, and Omid C. Farokhzad ${ }^{a, d *}$

aLaboratory of Nanomedicine and Biomaterials, Harvard Medical School, Department of

Anesthesiology, Brigham and Women's Hospital, Boston, Massachusetts 02115, United States

${ }^{b}$ Nanotechnology Research Center, Faculty of Pharmacy, Tehran University of Medical Sciences, Tehran, Iran

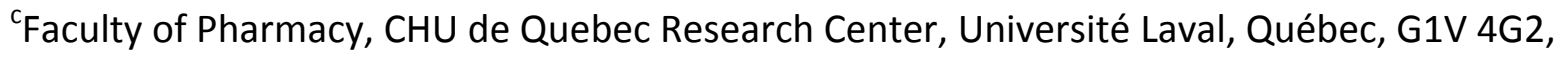
Canada

${ }^{\mathrm{d}}$ King Abdulaziz University, Jeddah 21589, Saudi Arabia

* Corrresponding authors at: Laboratory of Nanomedicine and Biomaterials, Harvard Medical School, Department of Anesthesiology, Brigham and Women's Hospital, Boston, Massachusetts 02115, United States. Tel.: +1.617.732.6093; fax: +1 617.730.2801.

Email address: (MM) mmahmoudi@bwh.harvard.edu; (OCF) ofarokhzad@bwh.harvard.edu 


\section{Summary}

Upon entering the physiological environment, nanoparticles (NPs) are immediately surrounded by a complex and tightly bound layer of biomolecules, or '(hard) protein corona'. The corona controls NP fate in vivo and becomes the interface with cells. One of nanomedicine's central goals is to make NPs capable of active targeting in both imaging and therapy. If the NP is not designed correctly, the resulting corona can cause mistargeting and aberrant biodistribution, unanticipated toxicity, and low therapeutic efficacy. Here we present groundbreaking concepts about nanobio interactions and discuss approaches to bypass protein corona issues and thus enhance the efficacy of NPs.

KEYWORDS: Nanoparticles; Protein corona; Targeting; Therapeutic efficacy 


\section{Introduction}

Despite advances in nanoparticle (NP) drug carriers and numerous publications, few NPs have made it to clinical trials, and even fewer have reached clinical practice. Recent reports revealed that the wide gap between bench discoveries and clinical translation is, at least in large part, due to our incomplete understanding of the interactions between NPs and living organisms [16].

Once in the body, the surface of NPs is rapidly covered by proteins to form a dynamic corona (the so-called "soft" corona) [6]; after a few minutes, NPs become surrounded by a long-lived ("hard") corona layer, which remains strongly adsorbed to their surfaces $[3,7]$. The affinity of the proteins for the surface of NPs is governed by a variety of complementary physical forces: Van der Waals interactions (VDW), hydrogen bonding ( $\mathrm{H}$-bond), as well as electrostatic and hydrophobic interactions (Figure 1) [8]. The relative importance of each of these forces depends on various parameters, including the size and the chemical properties of the nanoparticle surface [9]. VDW forces are weak and short-range electrostatic attractions between dipoles. $\mathrm{H}$-bonding between uncharged hydrophilic parts of the proteins (e.g., serine, threonine, asparagine and glutamine residues) and polar residues on the surface of the NP (e.g., hydroxyl on oxidized metals) is also possible. These interactions are individually stronger than VDW, but usually less abundant in aqueous physiological environments [8]. Materials that exhibit charged surface groups (e.g., amines or carboxylic acid) can also form cooperative electrostatic interactions with ionized proteins. These happen despite the presence of various ions in the biological fluids, because polyionic macromolecules can often better neutralize 
surface charges. Electrostatic interactions are believed to play a pivotal role in bringing proteins close to the surface of nanoparticles. Hydrophobic interactions can also occur on the surface of certain materials (e.g. polystyrene and polyesters). In proteins with secondary and tertiary structures, hydrophobic residues (e.g., alanine, valine, phenylalanine and others) often form rigid dehydrated regions, buried inside the core to minimize contacts with surrounding water. When weak forces bring these apolar regions in the vicinity of hydrophobic surfaces, the protein conformation can change and form strong interactions with the nanoparticle [10].

The effect of any NP on biological components such as cells (and vice versa) strongly depends on the corona composition, which in turn depends on the physicochemical properties (e.g., surface chemistry, size, shape, and stabilizer density) of the particle $[2,10,11]$. Therefore, while it is now possible to synthesize NPs with specific physicochemical properties, we have much to learn about how the formation of the protein corona affects the hypothetic therapeutic efficacy of NPs and can induce unwanted mistargeting and side effects $[12,13]$.

Current efforts in nanomedicine are centered on novel approaches to control the biological identity of NPs, optimizing in vivo therapeutic efficacy, and accelerating clinical transition [1420]. Recent findings reveal an urgent need for a deeper understanding of the biological identity of NPs, facilitating more predictable nanotherapeutic design and personalized nanomedicine $[16,21-26]$. In this review we will discuss recent findings relevant to diminishing the negative effects of the protein corona on active targeting and therapeutic efficacy of NPs. 


\section{Protein Corona Affects Active Targeting}

Surface functionalization of NPs with specific targeting ligands (e.g., aptamers, antibodies, and affibodies) is used for selective delivery of therapeutic biomolecules to desired anatomical sites. Targeted NPs have been shown to work perfectly in finding their target cells in vitro - if serumfree or low-protein medium (e.g., 10\% for cell culture) is used [27]. However, in vivo targeting efficacy was much poorer [28, 29]. In 2011, we posited that the formation of the protein corona is behind the wide disparity between in vitro and in vivo results, i.e., it may limit the accessibility of the targeting ligands to cell receptors[30]. In 2013, further experiments revealed that the protein corona can significantly cover the targeting ligand at the surface of NPs and cause mistargeting [31, 32].

As a model targeting reaction, Mirshafiee et al. [32] used copper-free click reaction between NPs and silicon substrates (Figure 2(A)). The silica NPs and silicon substrates were functionalized with bicyclononyne (BCN; a strained cycloalkyne) and azide groups, respectively. The targeting efficacy of the NPs toward silicon substrates was probed in the presence and absence of protein corona using a variety of techniques including fluorescence microscopy and scanning electron microscopy (SEM). It is noteworthy that protein coronas were formed in the presence of $10 \%$ (to mimic in vitro conditions) and $100 \%$ (to mimic in vivo conditions) serum. Both fluorescence microscopy and SEM images confirmed that protein corona substantially reduced the targeting efficacy of the NPs (Figure 2(B)-(D)). Quantitative analysis of fluorescence microscopy results revealed that the targeting efficiencies of NPs were reduced by $94 \%$ and $99 \%$ by in vitro and in vivo conditions, respectively. This suggests that, in this experimental 
setting, very small amounts of proteins can prevent nanoparticles from interacting with their target.

Beside simulating the targeting reactions, Salvati et al. [31] revealed the role of the proteinshielding effect in NP-cell interactions. They synthesized silica NPs functionalized with transferrin and observed their uptake by A549 lung epithelial cells through their specific interactions with transferrin receptors in the absence of any protein corona (Figure 2(E)). In the presence of a protein corona, however, they found that the corona covered the transferrin protein at the surface of NPs, substantially reducing the receptor-mediated uptake of NPs by A549 cells (Figure 2(F)). These findings clearly implicate the protein corona in the dramatic disparity between in vitro and in vivo outcomes of NP targeting efficacy.

Although they clearly highlight how the adsorption of proteins can alter the affinity of NPs for their intended targets, these experiments were conducted on material without intrinsic steric protection. The importance of protecting the NP surface to maintain specificity will be discussed in the section titled "Corona-Free Interfaces for High-Yield Targeting and Delivery Applications."

\section{Protein Corona Affects Drug Release}

A "magic bullet" to deliver drugs selectively to diseased cells was proposed more than 100 years ago [33]. However, though a single cure is generally unrealistic, selective drug delivery is particularly appealing in cancer therapy, where significant systemic toxicity limits the 
therapeutic index. Recent decades have witnessed a plethora of sophisticated drug-delivery systems to enhance safety and efficacy, including crosslinkable and stimuli-responsive targeted polymeric nanocarriers [34-36]. Despite much research designed to understand the controlledrelease profiles of therapeutic agents in vitro, the in vivo drug release profiles of these nanocarriers remains poorly understood. This is mainly because the critical role of the protein corona layer on the release profile has been overlooked, and the profiles were probed with very low concentrations ( $\sim 10 \%$ of serum) or even absence of proteins.

It is widely accepted that upon intravenous administration, polymeric micelles circulate systemically and deliver their encapsulated payload after uptake by target cells. Chen and coworkers $[37,38]$ explored further, with astonishing results. The authors employed a Förster resonance energy transfer (FRET) approach to gain a better understanding of the release of cargo molecules from polymeric micelles. DilC18(3) and DiOC18(3), a FRET pair, was loaded into the monomethoxy poly(ethylene glycol)-block-poly(D,L-lactic acid) micelles [37]. The authors found that FRET efficiency decreased even before intracellular uptake by the cells, suggesting that the micelles are unstable in the protein and membrane environment, which in turn affects their capacity for intracellular drug delivery. The same authors later demonstrated that FRET efficiency was significantly diminished within 15 min after intravenous injection when the same FRET pair in poly(ethylene glycol)-poly(D,L-lactic acid) (PEG-PDLLA) micelles were used [38], suggesting that DilC18 and DiOC18 rapidly escaped from the systemically circulating micelles. Furthermore, it was shown that the $\alpha$ - and $\beta$-globulins were major contributors to the fast release of encapsulated cargo in vivo. 
Cifuentes-Rius et al. [39] revealed that the protein corona can substantially change the release profile of the DNA payloads of various nanoparticles including gold nanorods, nanobones, and carbon nanotubes. They also found that the corona composition can be tuned to adjust the payload release profile. To acheive better underestanding on in vivo release profile, Behzadi et al. [40] probed the effect of protein corona on release profiles of various nanocarriers including polyethyleneglycol-co-fumarate (PEGF)-coated superparamagnetic iron oxide nanoparticles (SPIONs), poly(methyl methacrylate) polymeric nanocapsules, and commercialized Abraxane ${ }^{\circledR}$ nanocarriers (i.e., the albumin-bound drug paclitaxel). Monitoring of the drug-release profiles of these selected nanocarriers revealed that the protein corona substantialy reduced the burst effect of both protein-drug conjugates $\left(\right.$ Abraxane $^{\circledR}$ ) and drug-loaded PEGF-coated SPIONs (Figure 3). Conversely, the protein corona layer only slightly changed the release profile of polymeric nanocapsules, mainly due to the fact that capsule's shell is the limiting step for drug diffusion, i.e.,: 1) the hard corona shell is much thinner than the nanocapsule shell ( $\sim 10 \mathrm{~nm} v s$. $\sim 32 \mathrm{~nm}$ ) and 2) the nanocapsule shell is much harder (mainly because of its high glass transition temperature, $\sim 100 \circ \mathrm{C}$ ) than the corona shell. Therefore, though the protein corona might have negligible effects on drug release from all nanocapsules with monolithic membrane shells, it may play a critical role in the release profiles of payloads from porous nanocapsules.

According to these findings, the protein corona plays a crucial role in controlling the buffer effect of carriers on their drug payloads, which is important in reducing the side effects of anticancer drugs and modulating [if you mean that it increases their efficacy, you could say that directly; 'modulating' means a smaller effect and is neither positive nor negative] their therapeutic efficacy in vivo. In addition, these findings suggest that the currently available data 
on the release profile of various nanocarriers might not be valid in vivo, and those results should be reinterpreted considering the role of the protein corona.

\section{Controlling Protein-Corona Structure for High-Yield Active Targeting}

To evade the shielding effect of the protein corona (covering the targeting ligand) and create efficient in vivo active targeted nanoparticles (NPs), several strategies have been developed to control the composition of the protein corona in favor of targeting. In one strategy, the surface of NPs is engineered to recruit targeting proteins from the in vivo environment (e.g., human plasma). In other words, the protein corona composition is intentionally enriched with proteins to enhance targeting efficacy. There are two possible methods to achieve these goals. One is controlling the surface functionality [41] of NPs and the other is pre-coating the surface of NPs with specific proteins [42] to recruit similar proteins from plasma mainly via protein-protein interactions.

\section{Surface Functionality Directs Protein Corona Profile}

The surface functionality of NPs controls the protein corona composition and dictates interactions with target cells [41, 43-45]. For example, it has been demonstrated that surface modifications of alkyne-terminated thermally hydrocarbonized porous silicon NPs with dextran reduces the percentage of immune proteins (e.g., fibrinogen and immunoglobulin $\mathrm{G}$ ) in the protein corona [46]. This significantly lessens the chance of recognition by the immune system and the NPs' consequent clearance by phagocytosis. We have recently shown that modulating 
the surface functionalities of gold NPs substantially changes the composition of the protein corona [25]. More specifically, using a series of engineered cationic gold NPs (Figure 4(A)), we found that the formation of the protein corona was substantially dependent on hydrophobicity as well as the arrangement of chemical motifs on the NP surface. These NPs were taken up by macrophages, mainly through recognition of specific complement proteins in the corona. Thus, specific protein-induced phagocytosis by macrophages can be considered a simplified targeting model of corona-mediated NP uptake by a desired cell type.

To determine how different types of proteins contribute to macrophage recognition, we examined the correlation between macrophage uptake pattern and corona composition of gold NPs with various surface functionalities. We found that proteins from the complement, apolipoprotein, and coagulation categories had a substantial influence on macrophage uptake (Figure 4(B)). As predicted, the presence of complement proteins in the corona composition accelerated macrophage uptake, while immunoglobulins reduced uptake. Complement component 4 binding protein alpha (C4BPA) and immunoglobulin lambda constant 2 (IGLC2) had the highest positive and negative correlation coefficient $(r)$ with macrophage uptake, respectively (Figure $4(C)$ ). Interestingly, one of the main roles of C4BPA is to label apoptotic/necrotic cells for immune system clearance, which explains why positive $r$ with macrophage uptake was observed for NPs with C4BPA-rich corona composition $[47,48]$. An analysis of the proportion of the C4BPA and IGLC2 proteins in the corona composition of various NPs according to their uptake behavior suggests that those with higher C4BPA (i.e., hydrophilic NPs: NP1 and NP2) had high uptake, while NPs with low C4BPA (i.e., hydrophobic NPs) were subject to lower macrophage uptake. This demonstrates that modulating NP surface 
hydrophobicity is a straightforward way to reduce macrophage recognition (Figure 4(D)). Compared with hydrophobic NPs, hydrophilic NPs demonstrated lower uptake by macrophages, mainly due to the higher association of the IGLC2 proteins in their corona composition (Figure 4(E)). In addition to the predetermined proteins, Schöttle et al. [49] demonstrated that a substantial proportion of clustrin protein in the corona composition can significantly reduce a nanoparticle's uptake by macrophages. Thus we propose that the surface functionality of NPs plays a crucial role in regulating protein corona composition and, therefore, in targeting by macrophages. We have recently shown that tumor-associated macrophages play a critical role in the efficacy of NPs by acting as a slow-release reservoir of payload drugs into the tumor microenvironment [50]. Therefore, tuning the surface functionality of NPs could be a valuable means to control the tumor-associated macrophage recognition of NPs, and thereby their total efficacy and tumor distribution.

\section{Pre-coating with other proteins}

Another method of recruiting targeting proteins into the protein corona is to pre-coat NPs with specific proteins to attract desired proteins for the corona, mainly through protein-protein interactions [51]. Although there are extensive reports on the covalent and non-covalent attachment of proteins to the surface of NPs to enhance targeting efficacy (e.g., using ApoA-i and ApoB-100 to cross the blood-brain barrier and target brain tissue [52]), the role of ultimate in vivo identity of NPs in targeting remains unknown. To utilize the power of protein-protein interactions to control the ultimate biological identity of NPs, Mirshafiee and co-workers [42] 
used a pre-coating strategy to direct the formation of a protein corona that is targeted by immune cells (e.g., RAW 264.7 macrophages). They specifically intended to attract more opsonin-based proteins onto the surface of silica NPs to enhance opsonin-induced phagocytosis by macrophages. They chemically conjugated gamma-globulins (g-globulins) to the silica NPs to produce a controllable protein corona enriched with opsonins (e.g., various types of immunoglobulins). The liquid chromatography-mass spectrometry (LC-MS/MS) results confirmed the successful and substantial participation of immunoglobulins and complement component proteins in the corona composition of both uncoated (UC) NPs and NPs pre-coated with gamma-globulins (GG) (see Figure 5).

The protein corona created through this approach should significantly enhance the interactions of these particles with the Fc receptor on certain cells (e.g., natural killer cells, neutrophils, human platelets, and macrophages [53, 54]). Mirshafiee et al. [55] used macrophage RAW 264.7 cells to track the targeting capability of the immunoglobulin-decorated protein corona. However, the engineered protein corona (opsonin-rich) did not substantially increase NP uptake by macrophages (Figure 6(A)-(D)). More specifically, both flow cytometry and confocal microscopy confirmed that the GG-NPs had significantly higher uptake compared than either corona-UC-NPs or corona-GG-NPs. Theoretically, the immunoglobulin-rich protein corona should act as a ligand to bind to macrophages' receptors and provoke phagocytosis. Further immunolabeling experiments using western blotting revealed that immunoglobulins failed to bind to their target cell surface receptors because their active sites were not exposed to the outer layer of the protein corona (Figure 6(E)). Caracciolo et al. [56] also demonstrated that particles whose corona composition was highly enriched in opsonins could not bind to 
macrophage receptors and elicit phagocytosis, mainly due to the unfolding or unavailability of opsonin proteins in the outer corona layer (see Figure 7).

A thorough structural understanding of the proteins adsorbed on the surface of NPs is important in the development of therapeutic nano-biomaterials. In a quite interesting study, Kelly and co-workers [23] performed epitope mapping on transferrin-coated polystyrene NPs $220 \mathrm{~nm}$ in size. The authors used an immunogold-labeled monoclonal antibody (mTf) (Pro142Pro145) for an epitope proximal to the transferrin receptor binding region and a immunogoldlabeled polyclonal antibody (pTf) to recognize multiple epitopes simultaneously $[57,58]$. The results were instrumental in understanding the transferrin corona organization on the surface of the nanoparticle. The spatial organization and conformation governed the binding efficiency for this monoclonal antibody. Conversely, the polyclonal antibody would recognize the vast majority of the epitopes available on the surface for binding. The authors found that the concentration of the monoclonal antibody on the surface of the polystyrene NP was far lower than that of the polyclonal antibody (Figure 8(A)-(D)), which also produced a larger diameter in polystyrene NP, observed using differential centrifugal sedimentation (DCS) (Figure 8(E)). These results suggest that the transferrin (and thus the hard protein corona in general) is randomly organized on the surface of polystyrene NPs in various conformations, limiting the availability of an epitope for binding to its corresponding receptor.

Given the findings by various groups discussed above, future investigations in this area should focus on optimization of corona-mediated NP targeting strategies, both in terms of the recruitment of the desired plasma proteins and also their accessibility and 
orientation/folding/conformation in the corona layer. In other words, to fabricate NPs with high targeting efficacy, we must gain a thorough understanding of the composition of the outer layer of the corona and the accessibility of the functional motifs of desirable proteins to target cell receptors. In that regard, in vivo experiments might prove valuable to fully grasp the impact of all phenomena involved, in complete living organisms.

\section{Corona-Free Interfaces for High-Yield Targeting and Delivery Applications}

Another proposed strategy to enhance the targeting capability of NPs is to coat them with materials that inhibit interaction with proteins. If proteins are prevented from masking the engineered targeting ligands on the NP surface, there should be no corona-based loss of targeting efficacy.

One of the early materials proposed for preventing the formation of the corona was noncharged poly(ethylene glycols) (PEGs), which have good resistance against non-specific adsorption mainly because of their hydrogen bonding with water [59]. However, evaluations of coronas formed on PEGylated surfaces revealed they were composed mainly of fibrinogen, IgG, and apolipoprotein E [60-62]. As PEG clearly could not satisfy the urgent need for fabrication of corona-free NPs, researchers looking for another candidate material decided to pursue the promise of zwitterionic coatings in inhibiting corona formation [63, 64]. In very early evaluations, zwitterionic coatings demonstrated that they offered an alternative to increase NPs' biocompatibility and blood circulation time $[65,66]$. Using a series of zwitterionic NPs with different hydrophobicities, Moyano et al. [67] determined that no hard protein corona layer 
was formed. Therefore, zwitterionic NPs do facilitate the direct interaction of synthetic and biological components without the interference of a protein corona. This makes the combination of zwitterionic NPs with targeting ligands one of the most promising candidate strategies for targeting applications, mainly because they may be able to bypass the shielding effects (i.e., covering the targeting ligands) of the protein corona.

To probe the targeting efficacy of zwitterionic-coated NPs, Safavi et al. [68] fabricated biotincysteine-conjugated silica NPs; biotin was selected as the proper targeting molecule, and cysteine was used as a zwitterionic ligand to inhibit corona formation. The targeting capability of the biotin-cysteine-conjugated silica NPs and control targeted NPs (i.e., with biotin but without cysteine) were compared using modified silicon wafer substrates with streptavidin, which is a biotin receptor (Figure 9). The zwitterionic-coated NPs showed significantly higher targeting efficacy than the control NPs after incubation with human plasma. Similar results were obtained regarding the uptake properties of NPs by tumor cell lines that overexpress biotin receptors (Figure 10). These results clearly demonstrate the utility of zwitterionic coating in facilitating targeting of NPs.

It is now well understood that the uptake rate of cationic NPs by cells is significantly higher than that of anionic or neutral NPs [69-71], mainly because of the strong Coulombic interactions between cationic NPs and the anionic cell membrane. As the tumor microenvironment has lower $\mathrm{pH}(\sim 6.5)$ than normal tissue $[72,73]$, development of pH-responsive zwitterionic NPs with the capability to become cationic in the cancer microenvironment is of great interest. This platform could significantly enhance the NPs' uptake by cancerous cells, greatly reducing side 
effects in normal tissue. Such NPs would have promising therapeutic applications due to their high-yield tumor targeting, cancerous cell uptake, and cytotoxicity. Mizuhara et al. [74] proposed an innovative method to fabricate these NPs using a zwitterionic alkoxyphenyl acylsulfonamide coating (Figure 11(A)). The acylsulfonamide plays a role similar to that of carboxylic acid groups in response to changes in $\mathrm{pH}$ value [75]. The $\mathrm{pH}$ responsivity of acylsulfonamide group is controlled by the functional group attached to the sulfonyl group. Gold-coated NPs with this zwitterionic ligand showed formation of cationic NPs at tumor $\mathrm{pH}$ as a result of this ligand structure. In addition to this ligand, another zwitterionic gold NP (i.e., alkyl analogue) was used as control (see Figure 11(A)). Zeta potential screening of those NPs at various $\mathrm{pH}$ revealed the capability of these $\mathrm{pH}$-sensitive particles to assume a cationic state (Figure 11(B)). Probing the cellular uptake of both NPs by two cell lines (i.e., human cervical cancer cells/HeLa) and human microvascular endothelial cells/HMEC-1) revealed that the HeLa cells showed significant uptake of $\mathrm{pH}$-sensitive NPs at low $\mathrm{pH}$, while this effect was not seen in HMEC-1 cells (Figure $11(C)$ ). This is presumably due to the "cell vision" effect [76, 77]. It is noteworthy that cell vision is a variation of the detoxification strategies that any cell can use in response to toxins, drugs, and NPs [78]. In the lower $\mathrm{pH}$, the cationic NPs caused significantly higher toxicity in the HeLa cells compared to the control NPs (Figure 11(D)) because of the significantly higher uptake of the $\mathrm{pH}$-sensitive NPs into the cells (Figure 11(E)).

In a very recent report, Kang et al. [79] developed an innovative zwitterionic nanocarrier for high-yield delivery of anticancer drugs to tumor sites with negligible side effects to normal cells, mainly due to the rapid renal clearance of untargeted nanocarriers. As mentioned earlier, zwitterionic properties were used to reduce the protein corona on the surface of nanocarriers 
and thus reduce non-specific uptake by normal cells and immune system while enhancing the targeting capability of carriers toward the cancerous cells. For renal clearance of the untargeted nanocarriers from various tissues/organs, the hydrodynamic size of nanocarriers was designed to be $\sim<5.5 \mathrm{~nm}$. The nanocarriers were made of three parts: $\varepsilon$-polylysine (EPL) for zwitterionic modifications, near-infrared (NIR) fluorophores for bioimaging, and $\beta$-cyclodextrins ( $\beta$-CDs) for drug delivery (see Figure 12 for details). Due to the low protein adsorption to their surface, these zwitterionic nanocarriers escaped the immune system and showed significant capability for high-yield targeting of the tumor site in vivo (in both gastrointestinal stromal tumor (GIST)bearing xenograft and genetically engineered mice; see Figure $13(A)-(C))$. It is noteworthy that a fluorescent dye (Cy3 N-hydroxysuccinimide Ester)-conjugated imatinib was used in the nanocarrier to both target the tyrosine-kinase inhibitor for treating GIST [80] and track the biodistribution of the nanocarriers. The results (Figure $13(B)$ ) revealed that the nanocarriers that were distributed in other tissues (except tumor tissue) were rapidly cleared by the kidney and completely excreted through the bladder $24 \mathrm{hrs}$ after administration.

Histopathological analyses of the tumor site (Figure 13(D)) were performed to probe distribution of the drug-loaded nanocarriers in the tumor microenvironment. Fluorescence images of the nanocarriers revealed their accumulation in the boundaries of tumoral regions; the drug released by those carriers penetrated the intratumor environment. These findings clearly demonstrated that zwitterionic nanocarriers are capable of delivering hydrophobic drugs to the tumor site. Due to the acidic environment of tumor site [72, 73], the drug can then be released by forming a stable inclusion complex [79]. These newly developed zwitterionic 
nanocarriers are paving the way for theranostic nanoplatforms for safe, high-yield delivery of a wide variety of anticancer drugs.

\section{7- Personalized Protein Corona: New Challenge at the NanoBio Interface}

It has been shown that the protein source (i.e., human plasma, human serum, and fetal bovine serum) has a significant effect on the composition of the protein corona [81]; in turn, different corona compositions cause considerable changes in cellular uptake and intracellular traficking of NPs $[82,83]$.

It is well-recognized that various diseases may change the concentration/conformation of human plasma proteins; these include cancer, hemodialysis, diabetes, hypercholesterolemia, rheumatism, fauvism, hemophilia, and hypofibrinogenemia [84-89]. Changes in plasma protein profiles/biomarkers have been widely used for diagnosis of several diseases [90-94]. For instance, compared with healthy people, those who have undergone long periods of hemodialysis show significantly different amounts of proteins, including plasma vitamin D binding protein, clusterin, haptoglobin, hemopexin, apolipoprotein A-IV, complement factor B, and complement factor $\mathrm{H}[87,95]$. Similarly, although the exact reason for this finding is still under investigation, La Beck et al. [96] demonstrated that the clearance of doxorubicin liposomes was twofold lower in patients over 60 years old compared to younger patients [do you want to specify how much younger?]. 
It is increasingly being accepted that variation in plasma proteins caused by disease type can significantly change the composition of the protein corona at the surface of NPs $[14,22,97]$ and consequently their interactions with biological species [16, 98, 99].

For instance, it was demonstrated that silica and polystyrene NPs affect the conformation of fibrinogen protein in the corona produced by healthy individuals, substantially promoting the body's release of inflammatory cytokines [26]. In contrast, the corona of hypofibrinogenemia patients on the surface of the same NPs did not induce inflammatory cytokine release. This means that the biological identity (i.e., protein corona profile) of NPs should be designed to closely correspond to the disease type. Therefore, NPs should undergo disease-specific and even patient-specific design for highly efficient and safe clinical applications. Recent findings show that even healthy individuals may have different plasma compositions due to variation in their genetic background, age, gender, post-translational modification, and life style [100-105]. For instance, Colapicchioni et al. [105] showed significant variation among the protein corona profiles of healthy donors (Figure 14). This strongly suggests that in order to accelerate the clinical translation of NPs, researchers in the field should clearly report detailed information regarding the human serum/plasma (including type of disease, age, and gender) they use for each study; such precise information will minimize misinterpretation of protein corona data for in vivo applications [106].

Overlooking the central role of the newly understood "personalized protein corona" may be the major cause for the disappointing clinical results of the very few nanobio products that have reached clinical-stage evaluation [29]. 


\section{Conclusions and Future Perspectives}

As shown above, the protein corona directly affects the biological identity of nanoparticles, which may be totally different from their laboratory-designed identity. Such variation in nanoparticle' identity can significantly reduce expected drug targeting yield, drug release profile, and therapeutic efficacy. Current research in the field is focused on the development of new strategies to create nanoparticles with predictable/controllable biological identity. Among various surface coatings, zwitterionics have demonstrated a very promising role in inhibiting corona formation, enhancing both cell targeting and non-specific uptake by the immune system. In addition, coating a nanoparticle with specific proteins is another promising way to control corona formation (mainly via protein-protein interactions) and enhance targeting by recruiting targeting proteins from plasma. We expect that future efforts in the field will be centered on development of multifunctional zwitterionic coatings for fabrication of safe and corona-free NPs for high-yield therapeutic efficacy. In addition, the optimization of nanoparticles' surface properties by either protein pre-coating or specific chemical modifications can avoid the inhibitory role of protein corona by achieving high possible recruitment of the targeting proteins from plasma with highest accessibility of their active sites to the cell receptors.

As the majority of nanoparticles are injected intravenously, they have substantial interactions with endothelial cells. Recent findings revealed that $\mathrm{TiO}_{2}$ nanomaterials can affect the functionality of VE-cadherin (i.e., endothelial cells' adherens junction protein), thereby causing 
endothelial cell leakiness [107]. To design safe nanoparticles with high therapeutic efficacy, the effect of the protein corona on this newly discovered non-receptor-mediated mechanism should be carefully probed. The resulting information could help scientists design nanoparticles that interact minimally with VE-cadherin to diminish the risk of induced endothelial cell leakiness.

We also believe that a more comprehensive understanding of the personalized protein corona is necessary to advance the field and accelerate more predictable clinical translation. More specifically, nanoparticles should be custom-designed for specific diseases, as each disease may significantly affect the composition of the protein corona, changing its interactions with biological systems. 


\section{References:}

[1] K.K. Jain, BMC Med. 8 (2010) 83.

[2] M.P. Monopoli, C. Åberg, A. Salvati, K.A. Dawson, Nat. Nanotechnol. 7 (2012) 779-786.

[3] M. Mahmoudi, S.E. Lohse, C.J. Murphy, A. Fathizadeh, A. Montazeri, K.S. Suslick, Nano Lett. 14 (2013) 6-12.

[4] D. Walczyk, F.B. Bombelli, M.P. Monopoli, I. Lynch, K.A. Dawson, J. Am. Chem. Soc. 132 (2010) 57615768.

[5] M. Mahmoudi, Int. J. Biochem. Cell Biol. 75 (2016) 141-142.

[6] M. Mahmoudi, I. Lynch, M.R. Ejtehadi, M.P. Monopoli, F.B. Bombelli, S. Laurent, Chem. Rev. 111 (2011) 5610.

[7] S. Tenzer, D. Docter, J. Kuharev, A. Musyanovych, V. Fetz, R. Hecht, F. Schlenk, D. Fischer, K. Kiouptsi, C. Reinhardt, Nat. Nanotechnol. 8 (2013) 772-781.

[8] A.E. Nel, L. Mädler, D. Velegol, T. Xia, E.M. Hoek, P. Somasundaran, F. Klaessig, V. Castranova, M. Thompson, Nat. Mater. 8 (2009) 543-557.

[9] C.D. Walkey, J.B. Olsen, H. Guo, A. Emili, W.C. Chan, J. Am. Chem. Soc. 134 (2012) 2139-2147.

[10] J. Lazarovits, Y.Y. Chen, E.A. Sykes, W.C.W. Chan, Chem. Commun. 51 (2015) 2756-2767.

[11] C.Y. Tay, M.I. Setyawati, J. Xie, W.J. Parak, D.T. Leong, Adv. Funct. Mater. 24 (2014) 5936-5955.

[12] A.A. Saie, M. Ray, M. Mahmoudi, V.M. Rotello, Engineering the Nanoparticle-Protein Interface for Cancer Therapeutics, Nanotechnology-Based Precision Tools for the Detection and Treatment of Cancer, Springer International Publishing 2015, pp. 245-273.

[13] S. Zanganeh, R. Spitler, M. Erfanzadeh, A.M. Alkilany, M. Mahmoudi, Int. J. Biochem. Cell Biol. 75 (2016) 143-147.

[14] M.I. Setyawati, C.Y. Tay, D. Docter, R.H. Stauber, D.T. Leong, Chem. Soc. Rev. 44 (2015) 8174-8199.

[15] G. Caracciolo, Nanomed. Nanotech. Biol. Med. 11 (2015) 543-557.

[16] M. Azhdarzadeh, A.A. Saei, S. Sharifi, M.J. Hajipour, A.M. Alkilany, M. Sharifzadeh, F. Ramazani, S. Laurent, A. Mashaghi, M. Mahmoudi, Nanomedicine 10 (2015) 2931-2952.

[17] L. Bregoli, D. Movia, J.D. Gavigan-Imedio, J. Lysaght, J. Reynolds, A. Prina-Mello, Nanomed. Nanotech. Biol. Med. 12 (2016) 81-103.

[18] C. Corbo, R. Molinaro, A. Parodi, N.E.T. Furman, F. Salvatore, E. Tasciotti, Nanomedicine 11 (2016) $81-100$

[19] S. Schöttler, K. Landfester, V. Mailänder, Angew. Chem. Int. Ed. 55 (2016) 8806-8815.

[20] G. Caracciolo, O.C. Farokhzad, M. Mahmoudi, Trends Biotechnol. (2016), in press. DOI: 10.1016/j.tibtech.2016.08.011.

[21] M.A. Miller, S. Gadde, C. Pfirschke, C. Engblom, M.M. Sprachman, R.H. Kohler, K.S. Yang, A.M. Laughney, G. Wojtkiewicz, N. Kamaly, Sci. Transl. Med. 7 (2015) 314ra183-314ra183.

[22] M.J. Hajipour, S. Laurent, A. Aghaie, F. Rezaee, M. Mahmoudi, Biomater. Sci. 2 (2014) 1210-1221. [23] P.M. Kelly, C. Åberg, E. Polo, A. O'Connell, J. Cookman, J. Fallon, Ž. Krpetić, K.A. Dawson, Nat. Nanotechnol. 10 (2015) 472-479.

[24] A. Albanese, C.D. Walkey, J.B. Olsen, H. Guo, A. Emili, W.C.W. Chan, ACS Nano 8 (2014) 5515-5526. [25] K. Saha, M. Rahimi, M. Yazdani, S.T. Kim, D.F. Moyano, S. Hou, R. Das, R. Mout, F. Rezaee, M. Mahmoudi, V.M. Rotello, ACS Nano 10 (2016) 4421-4430.

[26] M. Rahman, M. Mahmoudi, SPIE BiOS, International Society for Optics and Photonics 2015, pp. 93380V-93380V-93388.

[27] F. Sonvico, S. Mornet, S. Vasseur, C. Dubernet, D. Jaillard, J. Degrouard, J. Hoebeke, E. Duguet, P. Colombo, P. Couvreur, Bioconjug. Chem. 16 (2005) 1181-1188. 
[28] S. Shanehsazzadeh, C. Gruettner, A. Lahooti, M. Mahmoudi, B.J. Allen, M. Ghavami, F.J. Daha, M.A. Oghabian, Contrast Media Mol. Imaging 10 (2015) 225-236.

[29] H. Ledford, Nature 533 (2016) 304-305.

[30] S. Laurent, M. Mahmoudi, Int. J. Mol. Epidemiol. Genet. 2 (2011) 367-390.

[31] A. Salvati, A.S. Pitek, M.P. Monopoli, K. Prapainop, F.B. Bombelli, D.R. Hristov, P.M. Kelly, C. Åberg, E. Mahon, K.A. Dawson, Nat. Nanotechnol. 8 (2013) 137-143.

[32] V. Mirshafiee, M. Mahmoudi, K. Lou, J. Cheng, M.L. Kraft, Chem. Commun. 49 (2013) 2557-2559.

[33] K. Strebhardt, A. Ullrich, Nat. Rev. Cancer, 8 (2008) 473-480.

[34] J. Shi, Z. Xiao, N. Kamaly, O.C. Farokhzad, Acc. Chem. Res. (2011).

[35] R.S. Zolot, S. Basu, R.P. Million, Nat. Rev. Drug Discov. 12 (2013) 259-260.

[36] Z. Bakhtiary, A.A. Saei, M.J. Hajipour, M. Raoufi, O. Vermesh, M. Mahmoudi, Nanomed. Nanotech. Biol. Med. 12 (2016) 287-307.

[37] H. Chen, S. Kim, L. Li, S. Wang, K. Park, J.-X. Cheng, Proc. Natl. Acad. Sci. U.S.A. 105 (2008) 65966601.

[38] H. Chen, S. Kim, W. He, H. Wang, P.S. Low, K. Park, J.-X. Cheng, Langmuir 24 (2008) 5213-5217.

[39] A. Cifuentes-Rius, H. de Puig, J.C.Y. Kah, S. Borros, K. Hamad-Schifferli, ACS Nano 7 (2013) 1006610074.

[40] S. Behzadi, V. Serpooshan, R. Sakhtianchi, B. Müller, K. Landfester, D. Crespy, M. Mahmoudi, Colloids and surfaces. B 123 (2014) 143-149.

[41] R. Mout, D.F. Moyano, S. Rana, V.M. Rotello, Chem. Soc. Rev. 41 (2012) 2539-2544.

[42] V. Mirshafiee, R. Kim, S. Park, M. Mahmoudi, M.L. Kraft, Biomaterials 75 (2016) 295-304.

[43] T. Mizuhara, D.F. Moyano, V.M. Rotello, Nano Today 11 (2016) 31-40.

[44] C.S. Kim, N.D. Le, Y. Xing, B. Yan, G.Y. Tonga, C. Kim, R.W. Vachet, V.M. Rotello, Adv. Healthc. Mater. 3 (2014) 1200-1202.

[45] Y. Jiang, S. Huo, T. Mizuhara, R. Das, Y.-W. Lee, S. Hou, D.F. Moyano, B. Duncan, X.-J. Liang, V.M. Rotello, ACS Nano 9 (2015) 9986-9993.

[46] C.-F. Wang, E.M. Mäkilä, C. Bonduelle, J. Rytkönen, J. Raula, S. Almeida, A. Närvänen, J.J. Salonen, S. Lecommandoux, J.T. Hirvonen, H.A. Santos, ACS Appl. Mater. Interfaces 7 (2015) 2006-2015.

[47] L.A. Trouw, A.A. Bengtsson, K.A. Gelderman, B. Dahlbäck, G. Sturfelt, A.M. Blom, J. Biol. Chem. 282 (2007) 28540-28548.

[48] J.H. Webb, A.M. Blom, B. Dahlbäck, J. Immunol. 169 (2002) 2580-2586.

[49] S. Schöttler, G. Becker, S. Winzen, T. Steinbach, K. Mohr, K. Landfester, V. Mailänder, F.R. Wurm, Nat. Nanotechnol. 11 (2016) 372-377.

[50] M.A. Miller, Y.-R. Zheng, S. Gadde, C. Pfirschke, H. Zope, C. Engblom, R.H. Kohler, Y. Iwamoto, K.S. Yang, B. Askevold, N. Kolishetti, M. Pittet, S.J. Lippard, O.C. Farokhzad, R. Weissleder, Nat. Commun. 6 (2015).

[51] C. Von Mering, R. Krause, B. Snel, M. Cornell, S.G. Oliver, S. Fields, P. Bork, Nature 417 (2002) 399403.

[52] J. Kreuter, T. Hekmatara, S. Dreis, T. Vogel, S. Gelperina, K. Langer, J. Control. Release 118 (2007) 54-58.

[53] L. Allen, A. Aderem, J. Exp. Med. 184 (1996) 627-637.

[54] P. Selvaraj, W.F. Rosse, R. Silber, Nature 333 (1988) 9.

[55] V. Mirshafiee, R. Kim, M. Mahmoudi, M.L. Kraft, Int. J. Biochem. Cell Biol. 75 (2016) 188-195.

[56] G. Caracciolo, S. Palchetti, V. Colapicchioni, L. Digiacomo, D. Pozzi, A.L. Capriotti, G. La Barbera, A. Laganà, Langmuir 31 (2015) 10764-10773.

[57] Y. Cheng, O. Zak, P. Aisen, S.C. Harrison, T. Walz, Cell 116 (2004) 565-576.

[58] A.B. Mason, S.L. Byrne, S.J. Everse, S.E. Roberts, N.D. Chasteen, V.C. Smith, R.T. MacGillivray, B. Kandemir, F. Bou-Abdallah, J. Mol. Recognit. 22 (2009) 521-529. 
[59] R. Wang, H. Kreuzer, M. Grunze, J. Phys. Chem. B 101 (1997) 9767-9773.

[60] H.R. Kim, K. Andrieux, C. Delomenie, H. Chacun, M. Appel, D. Desmaële, F. Taran, D. Georgin, P. Couvreur, M. Taverna, Electrophoresis 28 (2007) 2252-2261.

[61] J.L. Perry, K.G. Reuter, M.P. Kai, K.P. Herlihy, S.W. Jones, J.C. Luft, M. Napier, J.E. Bear, J.M. DeSimone, Nano Lett. 12 (2012) 5304-5310.

[62] R. Gref, M. Lück, P. Quellec, M. Marchand, E. Dellacherie, S. Harnisch, T. Blunk, R.H. Müller, Colloids Surf. B. 18 (2000) 301-313.

[63] K.P. García, K. Zarschler, L. Barbaro, J.A. Barreto, W. O'Malley, L. Spiccia, H. Stephan, B. Graham, Small 10 (2014) 2516-2529.

[64] G. Jia, Z. Cao, H. Xue, Y. Xu, S. Jiang, Langmuir 25 (2009) 3196-3199.

[65] F. Aldeek, M.H. Muhammed, G. Palui, N. Zhan, H. Mattoussi, ACS Nano 7 (2013) 2509-2521.

[66] R.R. Arvizo, O.R. Miranda, D.F. Moyano, C.A. Walden, K. Giri, R. Bhattacharya, J.D. Robertson, V.M. Rotello, J.M. Reid, P. Mukherjee, PloS One 6 (2011) e24374.

[67] D.F. Moyano, K. Saha, G. Prakash, B. Yan, H. Kong, M. Yazdani, V.M. Rotello, ACS Nano 8 (2014) 6748-6755.

[68] R. Safavi-Sohi, S. Maghari, M. Raouf, S.M. Jalalil, M.J. Hajipour, A. Ghassempour, M. Mahmoudi, ACS Appl. Mater. Interfaces (2016) in press, DOI: 10.1021/acsami.6b05099.

[69] A. Verma, F. Stellacci, Small, 6 (2010) 12-21.

[70] M. De, P.S. Ghosh, V.M. Rotello, Adv. Mater. 20 (2008) 4225-4241.

[71] C.M. Goodman, C.D. McCusker, T. Yilmaz, V.M. Rotello, Bioconjug. Chem. 15 (2004) 897-900.

[72] G. Helmlinger, F. Yuan, M. Dellian, R.K. Jain, Nat. Med. 3 (1997) 177-182.

[73] R.A. Cardone, V. Casavola, S.J. Reshkin, Nature Reviews Cancer, 5 (2005) 786-795.

[74] T. Mizuhara, K. Saha, D.F. Moyano, C.S. Kim, B. Yan, Y.K. Kim, V.M. Rotello, Angew. Chem. Int. Ed. 54 (2015) 6567-6570.

[75] P.K. Chakravarty, E.M. Naylor, A. Chen, R.S. Chang, T.-B. Chen, K.A. Faust, V.J. Lotti, S.D. Kivlighn, R.A. Gable, J. Med. Chem. 37 (1994) 4068-4072.

[76] M. Mahmoudi, S.N. Saeedi-Eslami, M.A. Shokrgozar, K. Azadmanesh, M. Hassanlou, H.R. Kalhor, C. Burtea, B. Rothen-Rutishauser, S. Laurent, S. Sheibani, Nanoscale 4 (2012) 5461-5468.

[77] M. Mahmoudi, S. Laurent, M.A. Shokrgozar, M. Hosseinkhani, ACS Nano 5 (2011) 7263-7276.

[78] S. Laurent, C. Burtea, C. Thirifays, U.O. Häfeli, M. Mahmoudi, PLoS One 7 (2012) e29997.

[79] H. Kang, J. Gravier, K. Bao, H. Wada, J.H. Lee, Y. Baek, G. El Fakhri, S. Gioux, B.P. Rubin, J.L. Coll, Adv. Mater. (2016) in press, DOI: 10.1002/adma.201601101.

[80] S. Béni, Z. Szakács, O. Csernák, L. Barcza, B. Noszál, Eur. J. Pharm. Sci. 30 (2007) 167-174.

[81] S. Laurent, C. Burtea, C. Thirifays, F. Rezaee, M. Mahmoudi, J. Colloid Interface Sci. 392 (2013) 431445.

[82] H.Y. Mao, S. Laurent, W. Chen, O. Akhavan, M. Imani, A.A. Ashkarran, M. Mahmoudi, Chem. Rev.

113 (2013) 3407-3424.

[83] S. Schöttler, K. Klein, K. Landfester, V. Mailänder, Nanoscale 8 (2016) 5526-5536.

[84] L. Kennedy, T.D. Mehl, E. Elder, M. Varghese, T.J. Merimee, Diabetes 31 (1982) 52-56.

[85] G. Engström, P. Lind, B. Hedblad, L. Stavenow, L. Janzon, F. Lindgärde, Circulation 105 (2002) 26322637.

[86] Y.-P. Lin, C.-Y. Yang, C.-C. Liao, W.-C. Yu, C.-W. Chi, C.-H. Lin, PloS One 7 (2012) e40232.

[87] S. Acharya, D. Dimichele, Haemophilia 14 (2008) 1151-1158.

[88] K.S. Kelly-Spratt, S.J. Pitteri, K.E. Gurley, D. Liggitt, A. Chin, J. Kennedy, C.-H. Wong, Q. Zhang, T.B. Buson, H. Wang, PLoS One 6 (2011) e19721.

[89] D. Brown, J. Clin. Pathol. 55 (2002) 1.

[90] K. Blennow, H. Hampel, M. Weiner, H. Zetterberg, Nat. Rev. Neurol. 6 (2010) 131-144.

[91] P.M. Ridker, N.J. Brown, D.E. Vaughan, D.G. Harrison, J.L. Mehta, Circulation 109 (2004) IV-6-IV-19. 
[92] O.M. El-Agnaf, S.A. Salem, K.E. Paleologou, M.D. Curran, M.J. Gibson, M.G. Schlossmacher, D. Allsop, FASEB J. 20 (2006) 419-425.

[93] S.M. Hanash, S.J. Pitteri, V.M. Faca, Nature 452 (2008) 571-579.

[94] J. Wei, W. Gao, C.-J. Zhu, Y.-Q. Liu, Z. Mei, T. Cheng, Y.-Q. Shu, Chin. J. Cancer 30 (2011) 407.

[95] H.B. Salt, Annals of the rheumatic diseases, 10 (1951) 46.

[96] N.M. La-Beck, B.A. Zamboni, A. Gabizon, H. Schmeeda, M. Amantea, P.A. Gehrig, W.C. Zamboni, Cancer Chemother. Pharmacol. 69 (2012) 43-50.

[97] G. Caracciolo, D. Caputo, D. Pozzi, V. Colapicchioni, R. Coppola, Colloids Surf. B 123 (2014) 673-678. [98] M. J. Hajipour, J. Raheb, O. Akhavan, S. Arjmand, O. Mashinchian, M. Rahman, M. Abdolahad, V. Serpooshan, S. Laurent, M. Mahmoudi, Nanoscale 7 (2014) 8978-8994.

[99] S. Palchetti, D. Pozzi, M. Mahmoudi, G. Caracciolo, J. Mater. Chem. B (2016).

[100] J. Brewer, O. Gurel, Nanotech. L. Bus. 6 (2009) 45.

[101] G.P. Chrousos, Nat Rev Endocrinol. 5 (2009) 374-381.

[102] D. Nedelkov, U.A. Kiernan, E.E. Niederkofler, K.A. Tubbs, R.W. Nelson, Proc. Natl. Acad. Sci. U.S.A. 102 (2005) 10852-10857.

[103] N.L. Anderson, N.G. Anderson, Mol. Cell. Proteomics 1 (2002) 845-867.

[104] Z.M. Ruggeri, T.S. Zimmerman, J. Clin. Invest. 65 (1980) 1318.

[105] V. Colapicchioni, M. Tilio, L. Digiacomo, V. Gambini, S. Palchetti, C. Marchini, D. Pozzi, S. Occhipinti, A. Amici, G. Caracciolo, Int. J. Biochem. Cell Biol. 75 (2016) 180-187.

[106] A.M. Alkilany, N.N. Mahmoud, F. Hashemi, M.J. Hajipour, F. Farvadi, M. Mahmoudi, Chem. Res. Toxicol. 29 (2016) 943-948.

[107] M. Setyawati, C. Tay, S. Chia, S. Goh, W. Fang, M. Neo, H. Chong, S. Tan, S. Loo, K. Ng, Nat. Commun. 4 (2013) 1673. 


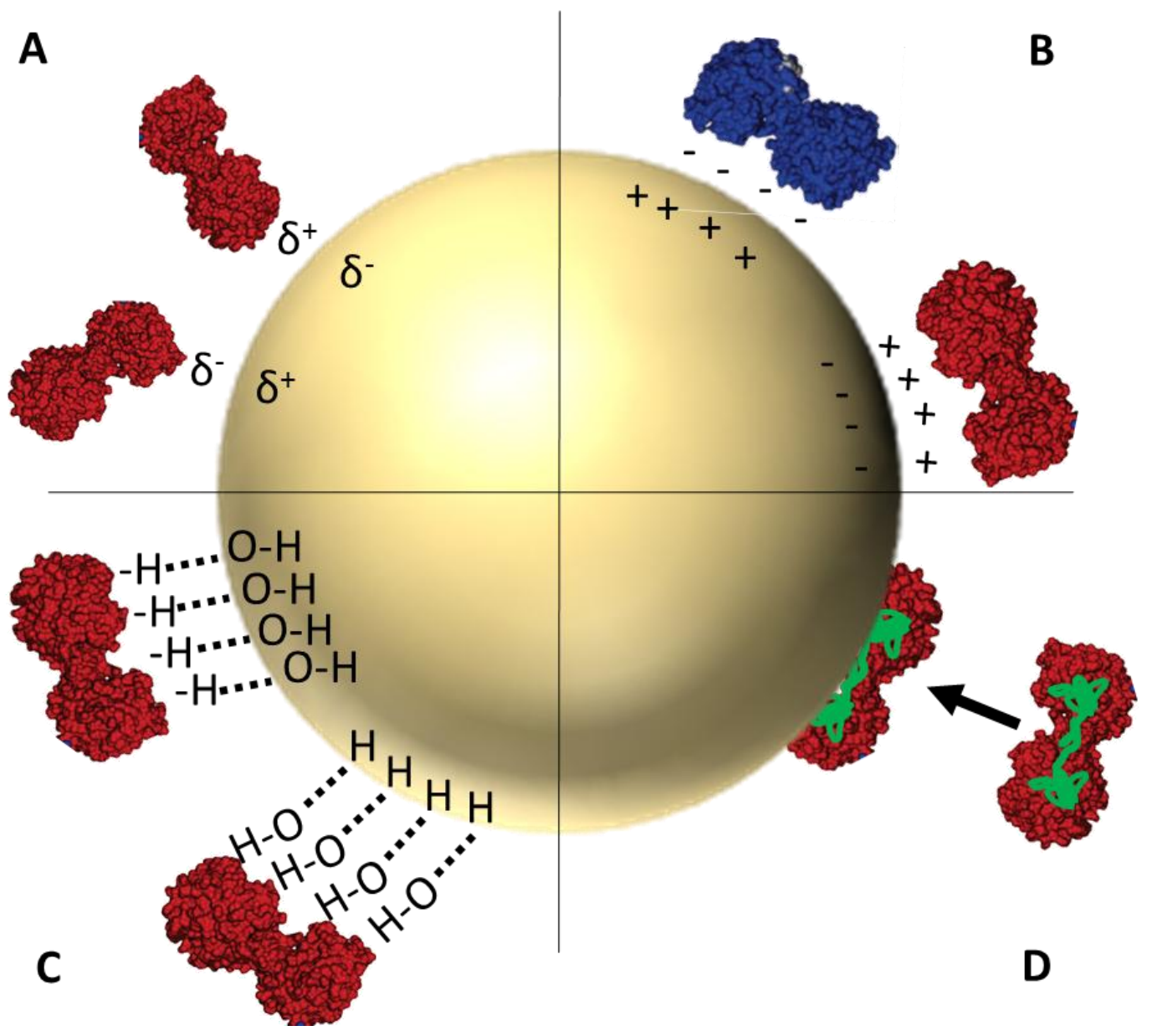

Figure 1. Schematic representation of biochemical interactions at the NanoBio interface, A) Van der Waals interaction, B) Electrostatic interaction, C) Hydrogen bonding and D) Hydrophobic (depicted as green) interaction. 

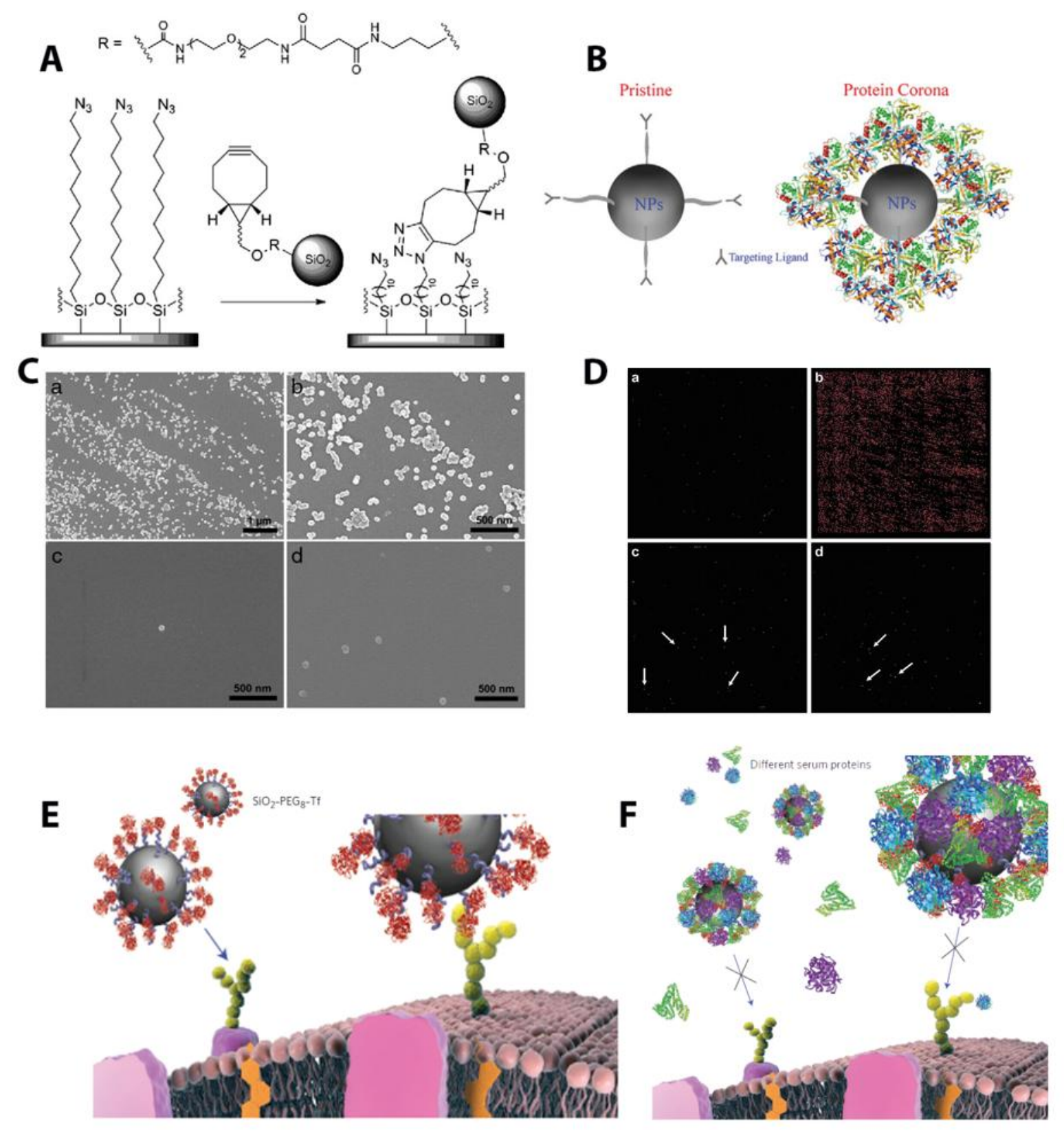

Figure 2. (A) Schematic illustration of the model targeting reaction based on copper-free click reaction between the bicyclononyne groups on the NPs and the azides on the modified silicon substrate. (B) Cartoon showing how the protein corona can blind the targeting species on the surface of NPs. (C) Scanning electron microscopy images of the attached NPs to the surface of modified silicon substrates, with azide groups, in the absence ( $a$ and $b$ ) and presence of protein 
corona with serum concentration of (c) $10 \%$ and (d) 100\%. (D) Fluorescence microscopy images of $5 \mathrm{~mm}$ by $5 \mathrm{~mm}$ silicon substrates after incubation with NPs demonstrating (a) negligible nonspecific binding and (b) numerous specific binding of pristine NPs to the azide-free and the azide-functionalized substrates, respectively. (c and d) Presence of protein corona, after incubation of particles with (c) $10 \%$ or (d) $100 \%$, on the surface of NPs significantly reduced their attachment to the azide-functionalized substrates. Arrows designate individual NPs. Schematics showing (E) the recognition and (F) loss of targeting for transferrin (Tf)-conjugated NPs in the absence and presence of protein corona, respectively. Printed with permission from Nature publishing group and Royal society of chemistry. [31, 32]. 
A

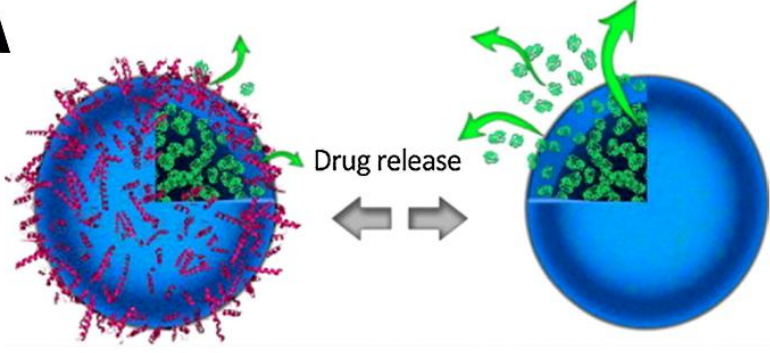

C

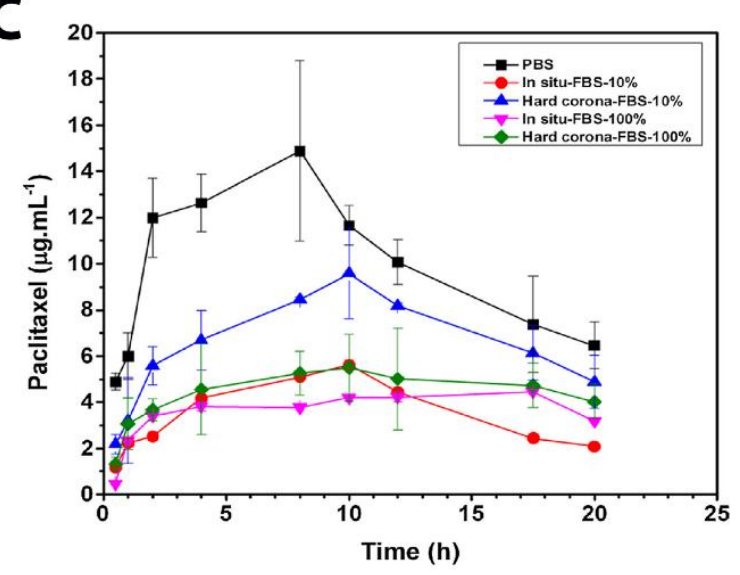

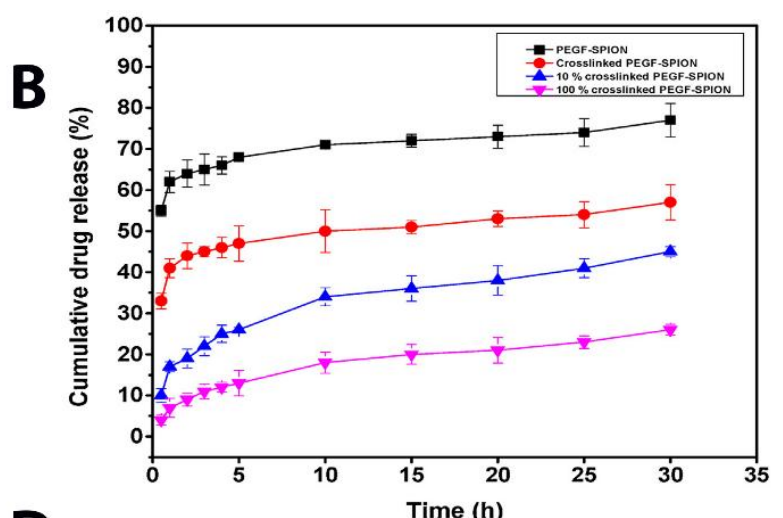

D

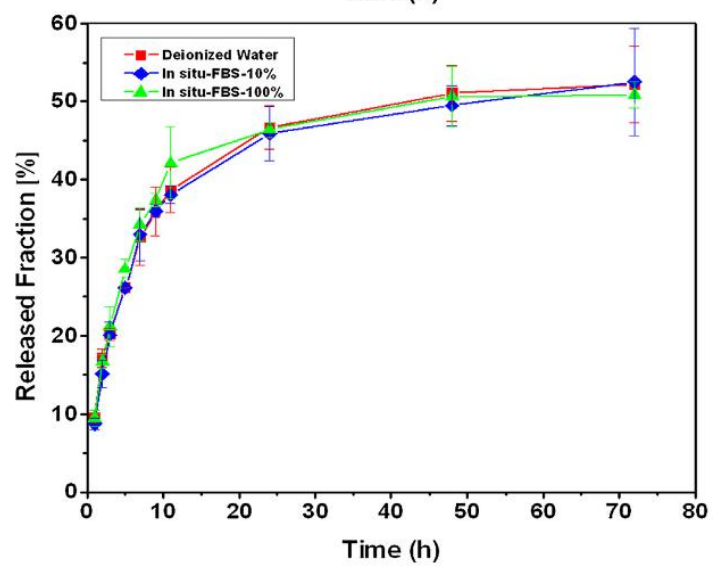

Figure 3. (A) Cartoon showing the inhibiting role of protein corona on drug release. (B) Release profile of tamoxifen from various coated SPIONs (non-crosslinked and crosslinked PEGF) in the absence and presence of FBS (10\% and $100 \%)$ over $30 \mathrm{~h}$. (C) Paclitaxel release profile from Abraxane in the absence and presence of FBS (with various concentrations; i.e., $10 \%$ and $100 \%$ ) in both in situ and after removal of excess proteins. (D) Release profile of 4-nitroanisole from nanocapsules, in the presence and absence of protein corona, over $80 \mathrm{~h}$. Printed with permission from Elsevier publishing group [40]. 


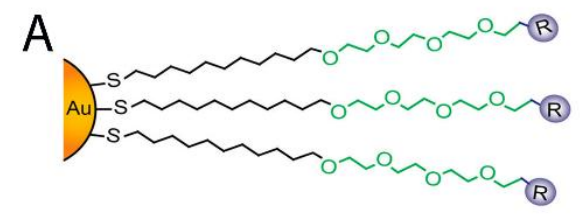

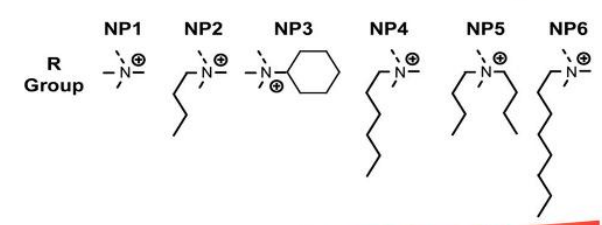

$\begin{array}{llllllll}\log P & 0.02 & 1.61 & 2.05 & 2.66 & 3.19 & 3.72\end{array}$

\begin{tabular}{|c|c|c|c|c|}
\hline nanoparticle & $\begin{array}{c}\text { hydrodynamic } \\
\text { size (nm) in } 5 \\
\text { mM PB pH } \\
7.4\end{array}$ & $\begin{array}{l}\text { hydrodynamic } \\
\text { size }(\mathrm{nm}) \text { in } \\
\text { cell culture } \\
\text { media }\end{array}$ & $\begin{array}{c}\text { zeta } \\
\text { potential } \\
\text { (mV) in } 5 \\
\mathrm{mM} \mathrm{PB} \mathrm{pH} \\
7.4\end{array}$ & $\begin{array}{l}\text { calculated } \\
\log \mathrm{P} \text { of the } \\
\text { ligand } \\
\text { headgroup }\end{array}$ \\
\hline NP1 & $10.9 \pm 3.1$ & $11.4 \pm 3.3$ & $15.2 \pm 6.9$ & 0.02 \\
\hline NP2 & $12.8 \pm 2.9$ & $10.1 \pm 3.0$ & $17.8 \pm 7.9$ & 1.61 \\
\hline NP3 & $9.9 \pm 2.8$ & $13.0 \pm 2.7$ & $21.7 \pm 7.6$ & 2.05 \\
\hline NP4 & $10.4 \pm 2.8$ & $10.0 \pm 3.0$ & $19.7 \pm 4.8$ & 2.66 \\
\hline NP5 & $11.0 \pm 3.0$ & $10.7 \pm 2.4$ & $24.9 \pm 9.9$ & 3.19 \\
\hline NP6 & $9.9 \pm 2.9$ & $11.8 \pm 3.8$ & $18.2 \pm 8.6$ & 3.72 \\
\hline
\end{tabular}

B
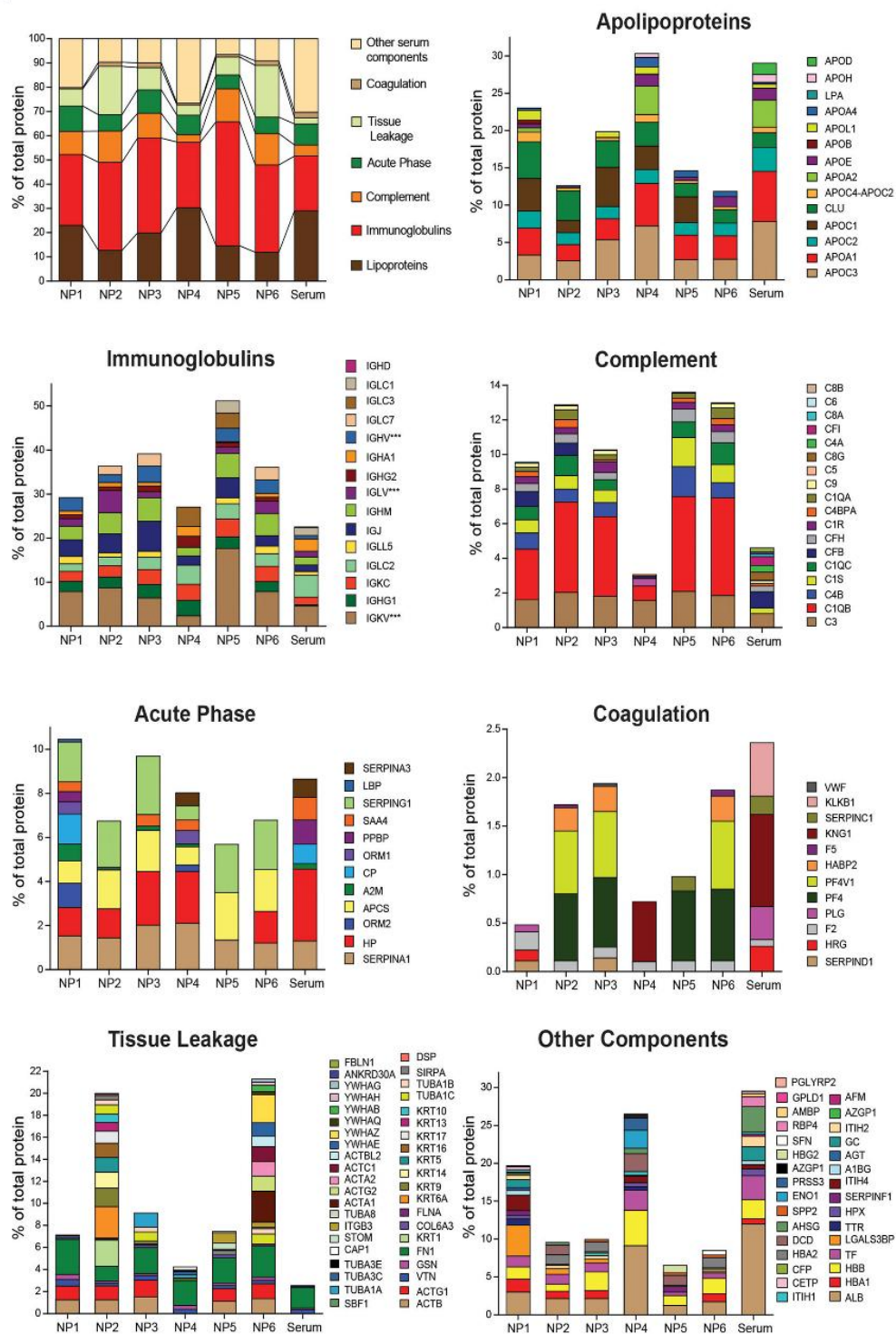

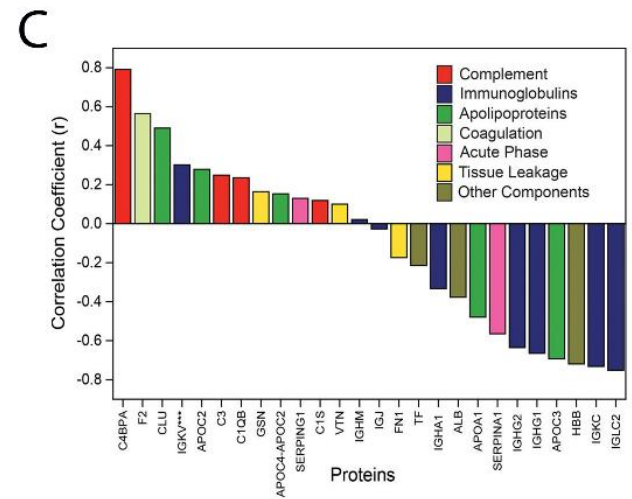

D

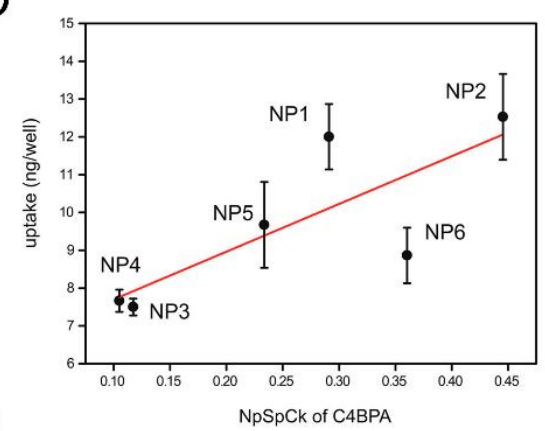

E

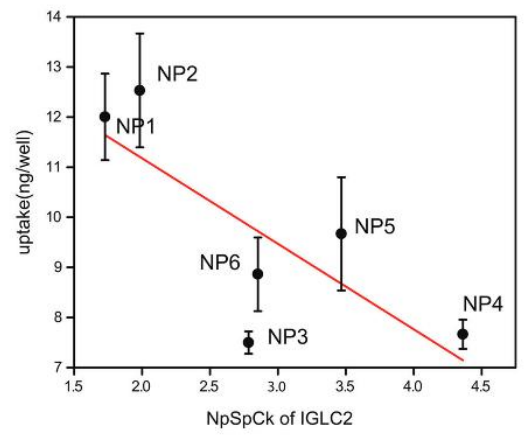


Figure 4. A. Physicochemical properties of gold NPs with varying hydrophobicity. Log P demonstrates the comparative hydrophobicity of the head-groups. B. Classification of the associated proteins in the corona. C. Correlation between macrophage uptake and protein corona composition (selected proteins form different categories with large positive or negative correlation). Correlation between macrophage uptake of various nanoparticles and their specific corona proteins: (D) C4BPA and (E) IGLC2. Printed with permission from American Chemical Society publishing group [25]. 


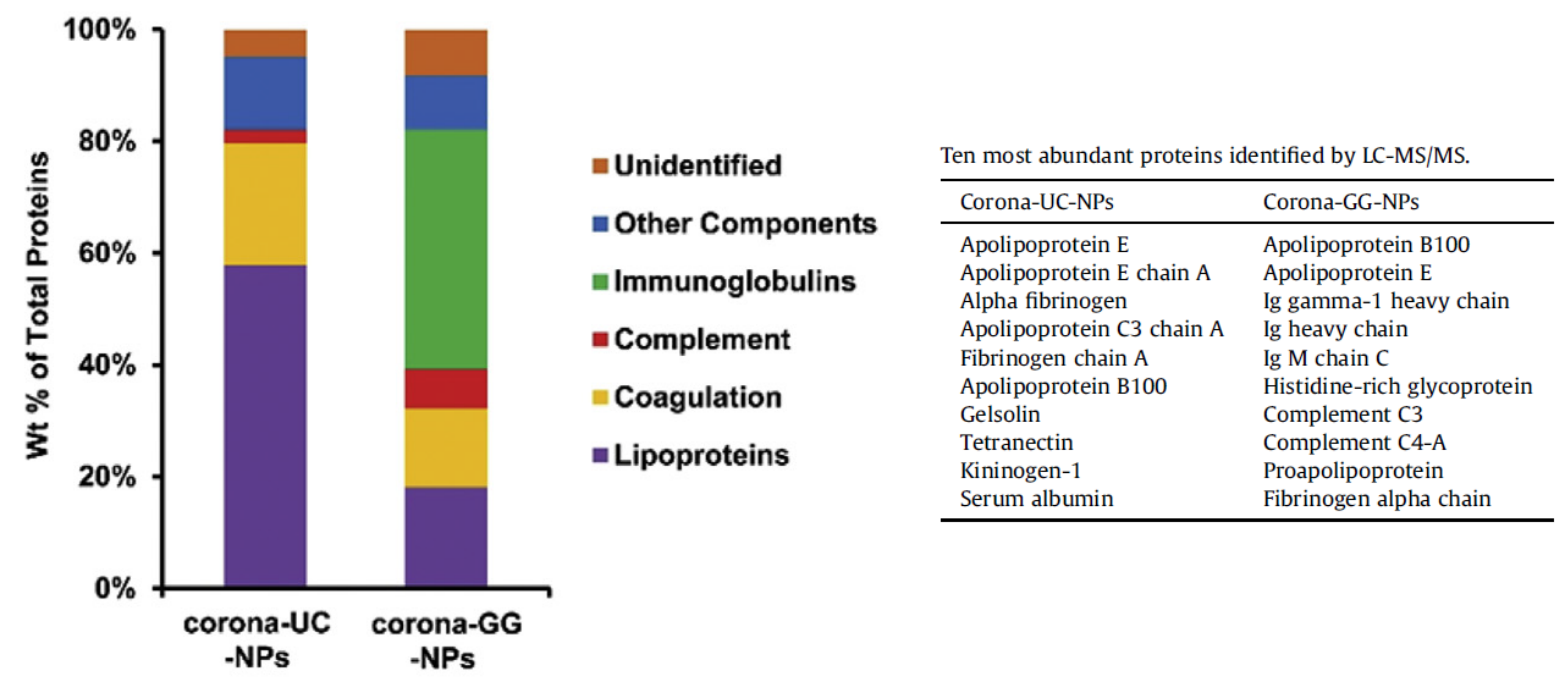

Figure 5: The normalized abundance of identified proteins in the protein corona of the uncoated (UC) NPs and the NPs pre-coated with gamma-globulins (GG) according to protein classification. Printed with permission from Elsevier publishing group[42]. 

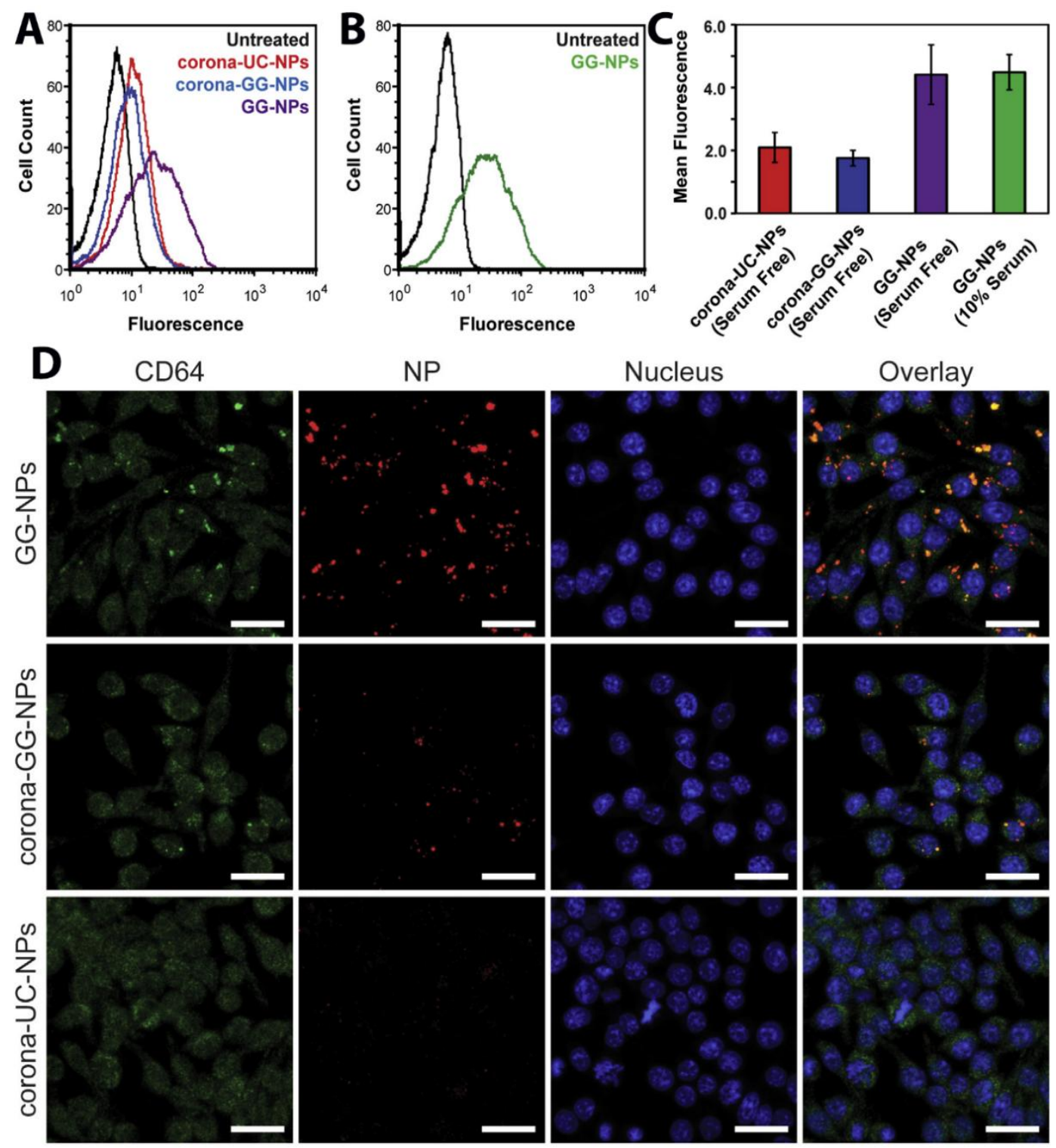

E (1)

(2)

(3)

(4)

Figure 6: Flow cytometry results show the uptake of various nanoparticles in (A) serum-free and

(B) $10 \%$ serum medium. (C) Quantification of the flow cytometry results in a bar graph format.

(D) Confocal microscopy images of RAW264.7 cells demonstrate the highest colocalization with the CD64 receptor for the GG-nanoparticles compared to others, including corona-coated GG- 
nanoparticles. Nanoparticles, anti-CD64, and cell nucleus are respectively shown in red, green, and blue. Scale bars are $20 \mathrm{~mm}$. (E) Immuno-dot blot assays showing the amount of the exposed immunoglobulins at the surfaces of various NPs. Higher amounts of immunoglobulins were detected on the GG-NPs (3) compared to the corona-UC-NPs (1), corona-GG-NPs (2), and GG-NPs that had been exposed to medium consisting of DMEM/serum (9/1 vol/vol) (4). Printed with permission from Elsevier publishing group [42]. 


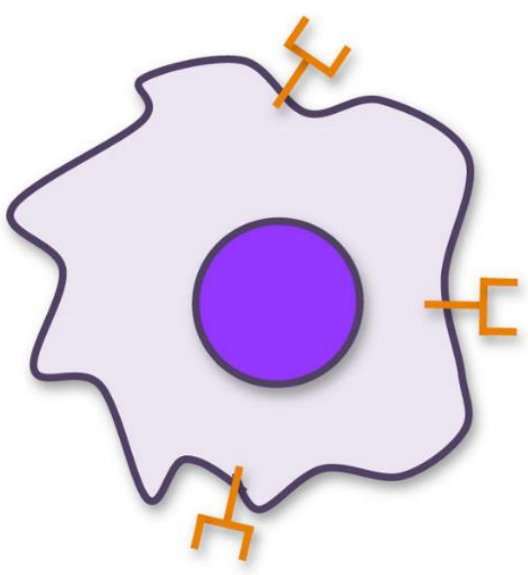

Macrophage

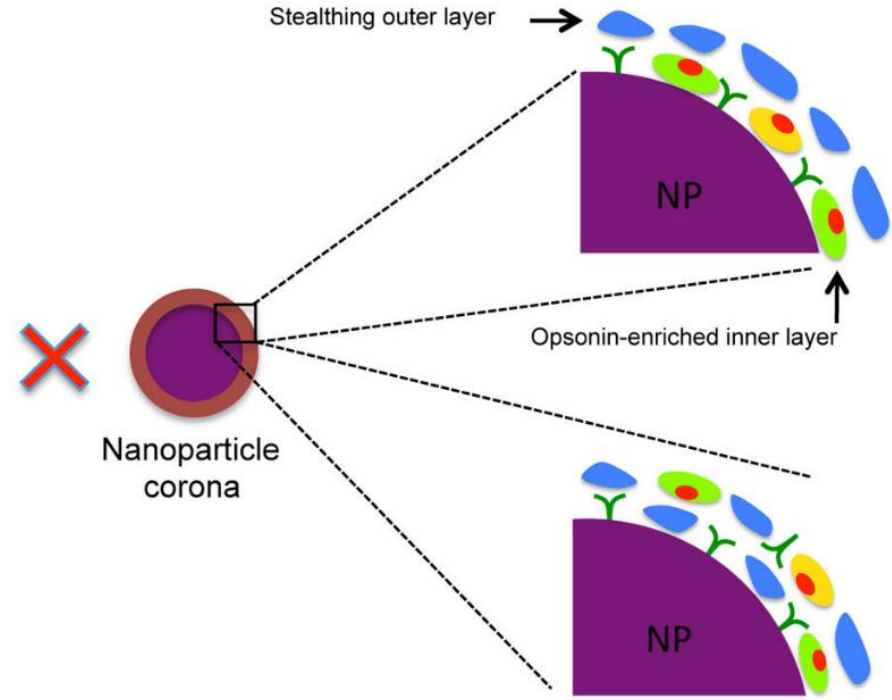

$\uparrow$

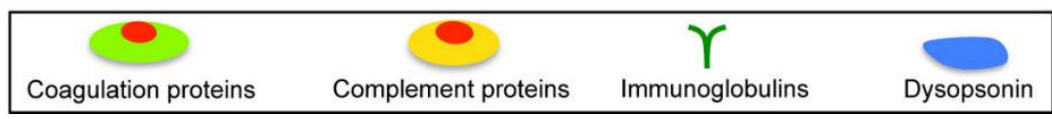

Figure 7: Schematic showing unfolding and the epitopes buried inside targeting proteins (e.g., immunoglobulins, complement factors, and coagulation proteins) for Fc receptors of macrophages. Although corona composition is enriched with opsonins, the unavailability of these proteins to cell receptors inhibits a significant increase in NP uptake by immune cells. Printed with permission from American Chemical Society publishing group [56]. 

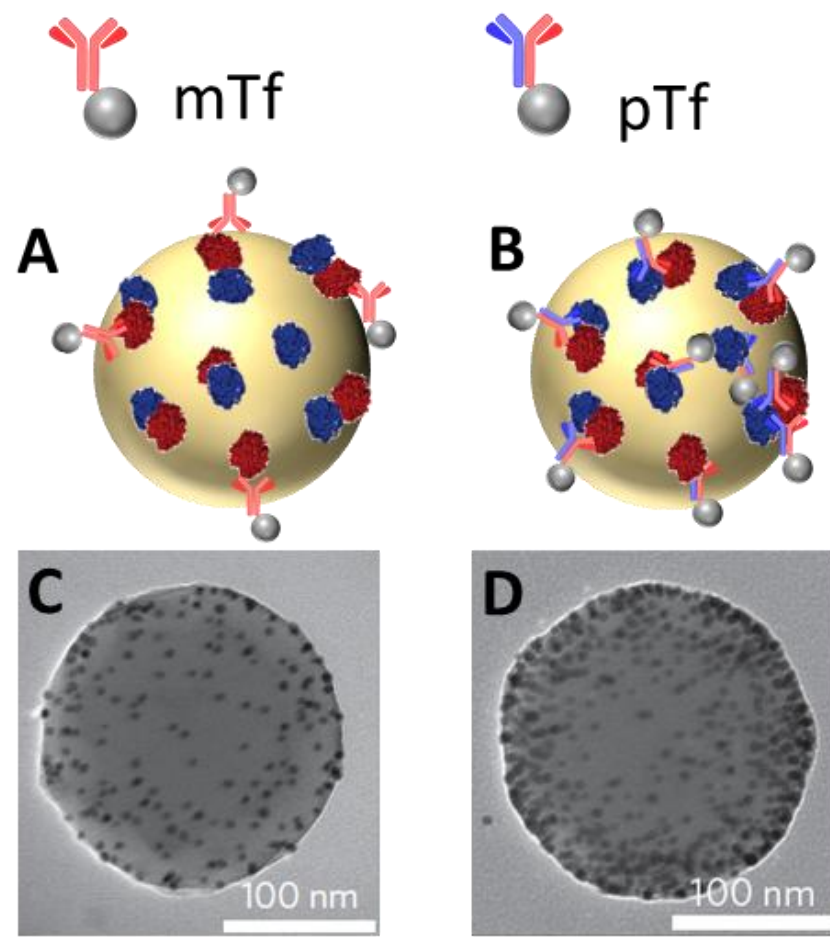

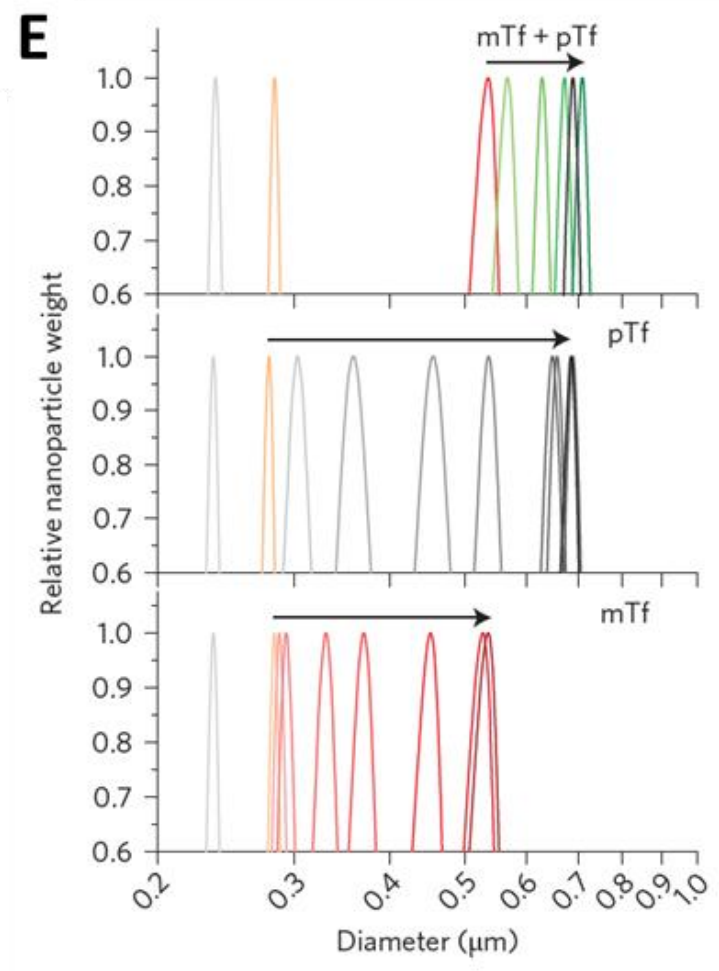

Figure 8: Schematic representation of transferrin-coated polystyrene particles incubated with similar concentrations of immunogold-labeled monoclonal (mTf) (A), polyclonal (pTf) (B) and their corresponding TEM images (C) and (D) respectively. (E) Differential Centrifugal Sedimentation (DCS) distributions, in apparent diameter, for increasing concentrations of double-titration (mTf + pTf) transferrin-coated polystyrene particles followed by monoclonal (mTf) and polyclonal (pTf) immunogold labels. Polystyrene in grey followed by transferrin-coated polystyrene in orange, then successive changes in color referring to incremental changes in label concentration. Printed with permission from Nature publishing group[23]. 


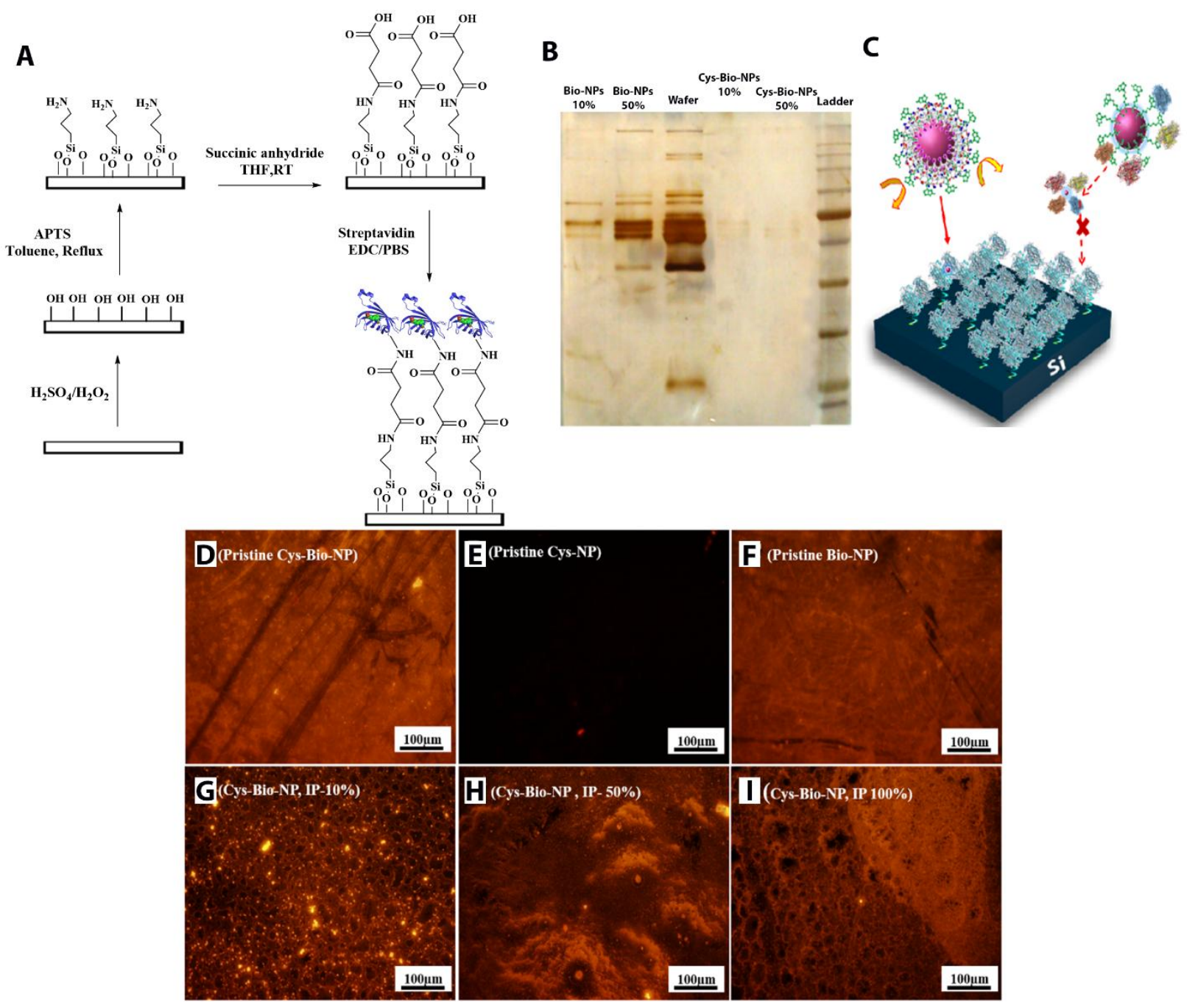

Figure 9. (A) Schematic illustration of surface modification of silicon substrates with streptavidin. (B) SDS-PAGE gels showing the hard-corona profiles of the biotin-conjugated silica NPs (Bio-NPs) and cysteine-biotin-conjugated silica NPs (Cys-Bio-NPs) after incubation with different human plasma concentrations (10-50\%) and protein adsorbed on the surface of modified wafers in $50 \%$ plasma after two washes with PBS. (D-E) Fluorescence microscopy images of the modified silicon substrates after incubation with various NPs including pristine Cys-Bio-NPs (cysteine-biotin-conjugated silica NPs), Cys-NPs, and Bio-NPs. Fluorescence Images of the attached (D) pristine Cys-Bio-NPs to the substrate showing their strong binding to 
streptavidin, (E) pristine Cys-NPs attached to the streptavidin substrate showing no specific interactions, and (F) pristine Bio-NPs demonstrating strong binding to the substrate. Fluorescence images demonstrating numerous conjugations of the corona-coated Cys-Bio-NPs after incubation with (G) $10 \%,(\mathrm{H}) 50 \%$, and (I) $100 \%$ human plasma, showing the strong role of zwitterionic coating in avoiding the mis-targeting effects of the protein corona. Printed with permission from American Chemical Society publishing group[68]. 
$\mathbf{A}$

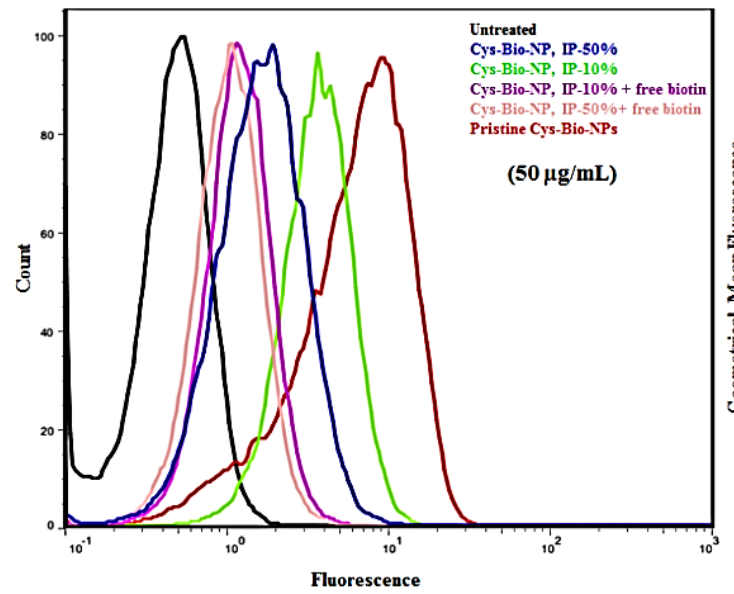

C

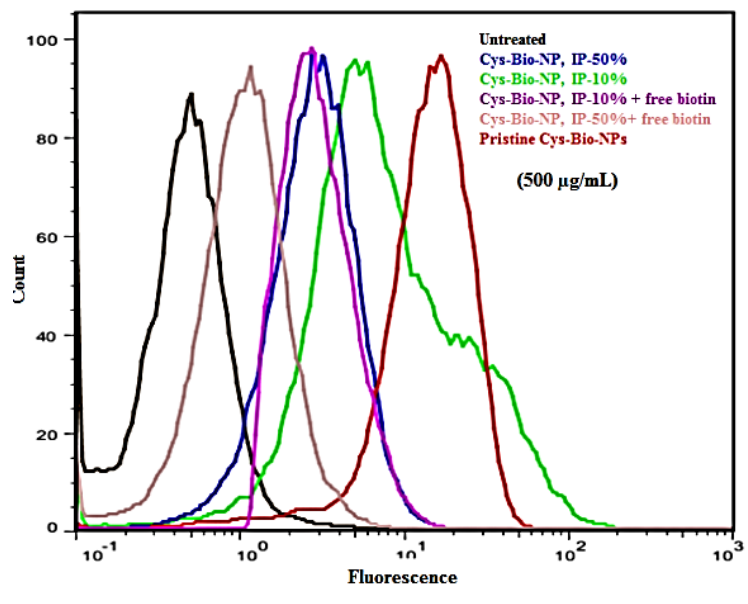

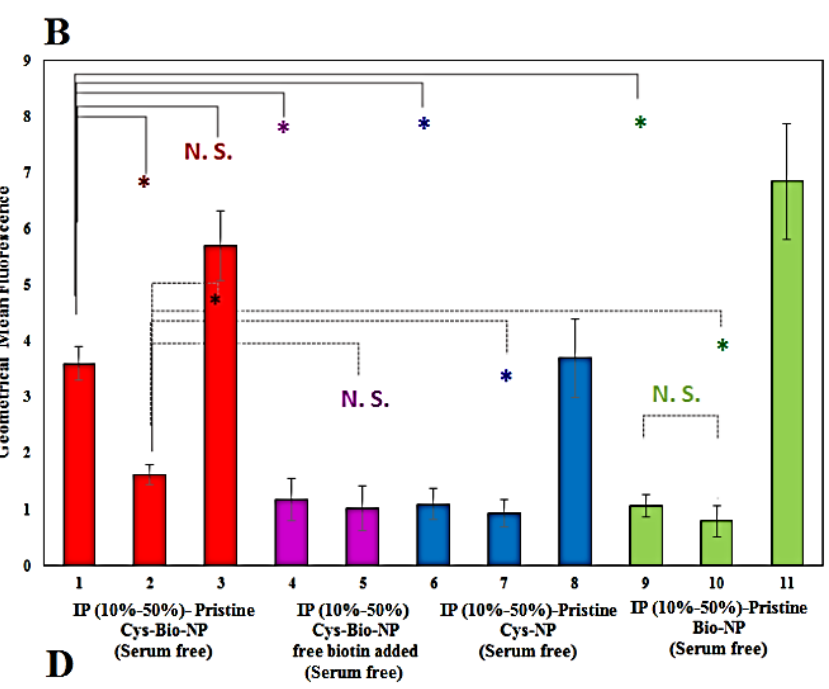

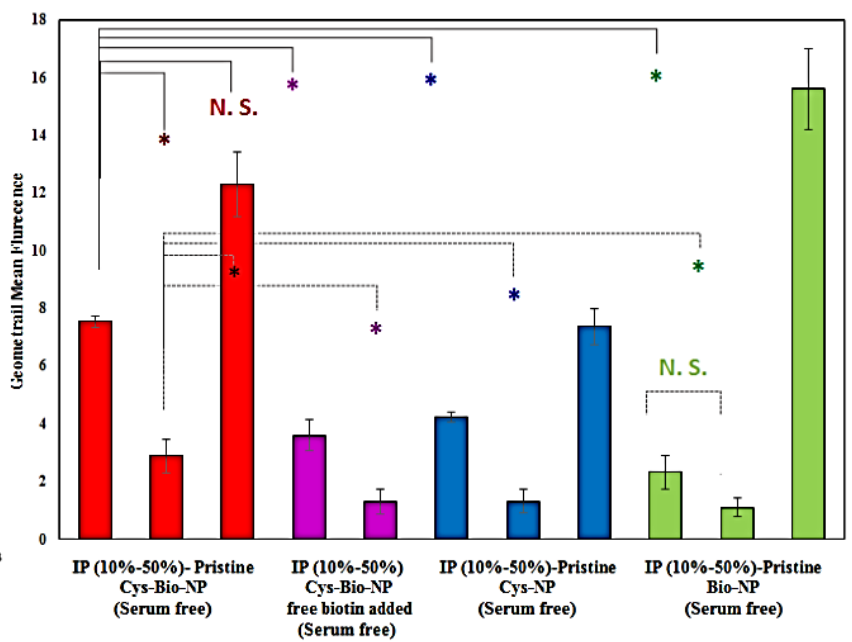

Figure 10. Flow cytometry results indicating the uptake of various cysteine-biotin-conjugated silica NPs (Cys-Bio-NPs) by adenocarcinoma human alveolar basal epithelial cells in serum-free medium (SF-DMEM). NP at concentrations of (A) 50 and (B) $500 \mu \mathrm{g} / \mathrm{mL}$ with bar graphs (B and D) showing geometrical mean fluorescence in different states (including pristine), after human plasma treatment ( $10 \%$ and $50 \%$ ) and after addition of free biotin (to block specific uptake by biotin receptors). The data are shown as mean \pm SD $(n=3)$, * denotes ( $p$-value $<0.05)$, and N.S. denotes not significant. Printed with permission from American Chemical Society publishing group[68]. 


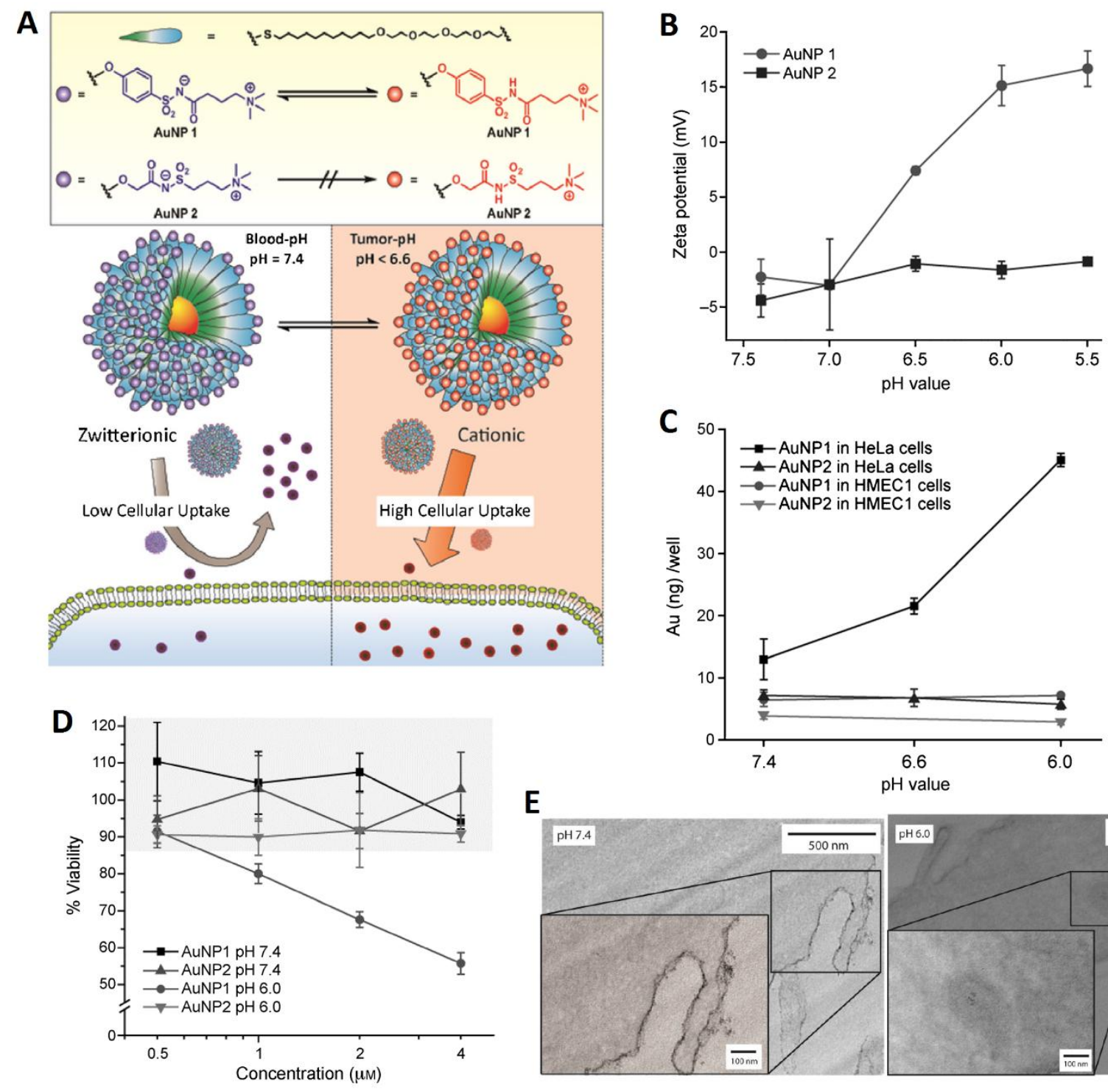

E

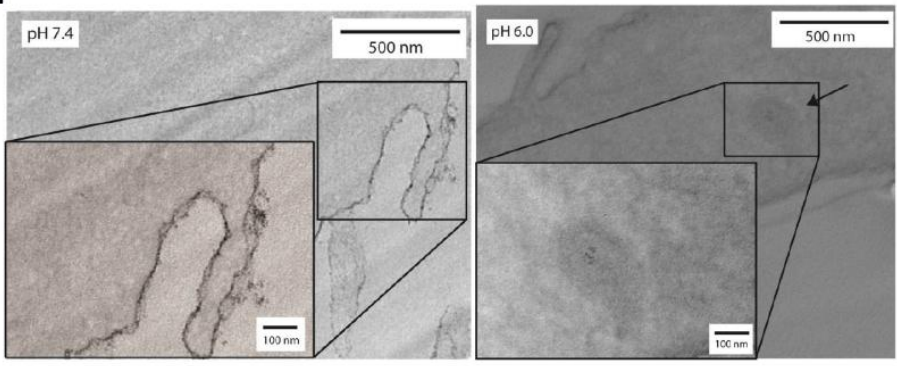

Figure 11. (A) Schematic showing the chemical structure of the pH-responsive (AuNP1) and control (AuNP2) gold nanoparticles and cartoon showing how pH-responsive nanoparticles can enhance cellular uptake in the tumor microenvironment (with lower $\mathrm{pH}$ than the normal tissue). (B) Variation of zeta potential of AuNPs1 and AuNPs2 against $\mathrm{pH}$ values showing the cationic structure of AuNPs1 in acidic $\mathrm{pH}$. (C) Cellular uptake of AuNPs1 and AuNPs2 after $3 \mathrm{~h}$ incubation with HeLa and HMEC-1 cells showing the significantly higher uptake of AuNPs1 in HeLa cells at lower pH. (D) Viability of HeLa cells after incubation with AuNPs1 and AuNPs2 (for 
$72 \mathrm{~h}$ ) revealing the cytotoxicity of AuNPs1 in the low $\mathrm{pH}$. (E) Transmission electron microscopy images of the incubated HeLa cells with AuNPs1 (for $3 \mathrm{~h}$ ) showing the nanoparticles present on the cell membrane at normal $\mathrm{pH}$ and their endosomal uptake at lower $\mathrm{pH}$ 6.0. Printed with permission from Wiley publishing group [74]. 

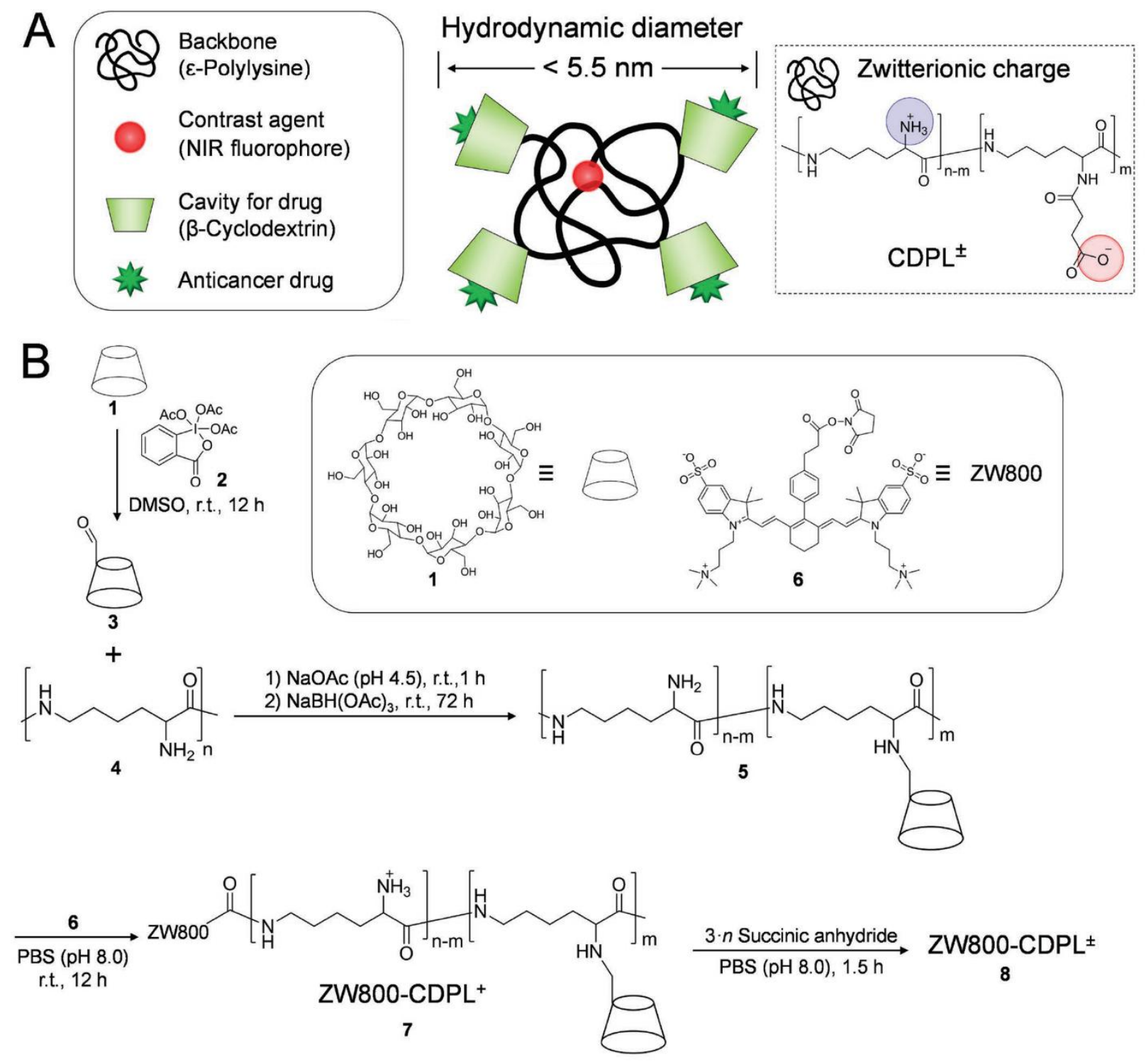

Figure 12. Schematic representation of the zwitterionic cyclodextrins-polylysine (CDPL) nanocarrier. B) The synthesis procedure of zwitterionic CDPL conjugated with zwitterionic nearinfrared fluorophore (i.e., ZW800-1C). Printed with permission from Wiley publishing group [79]. 

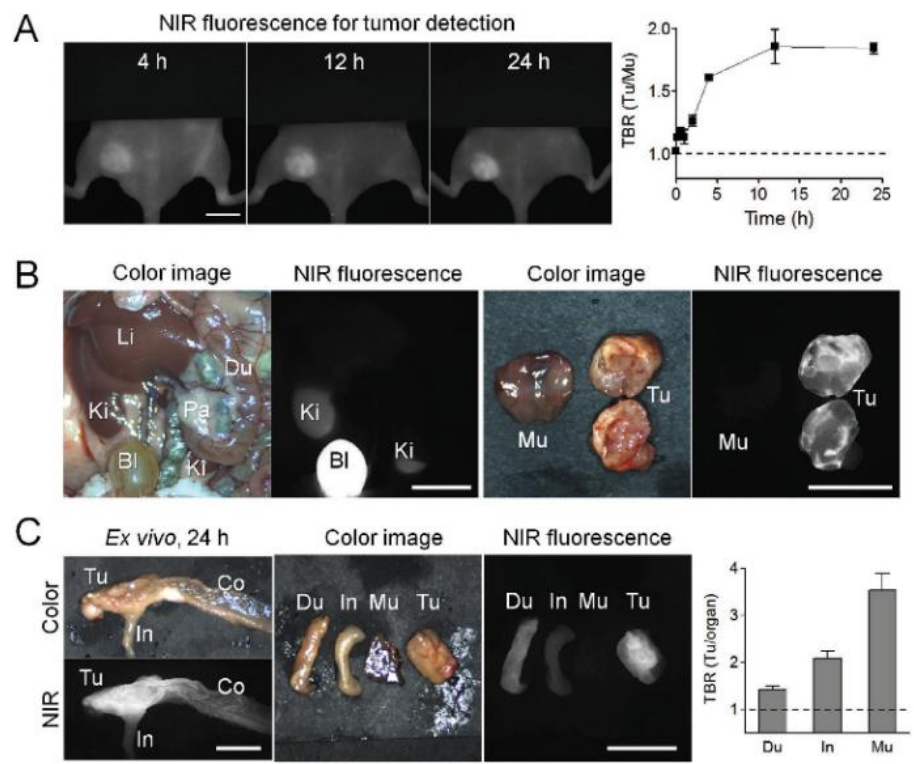

D

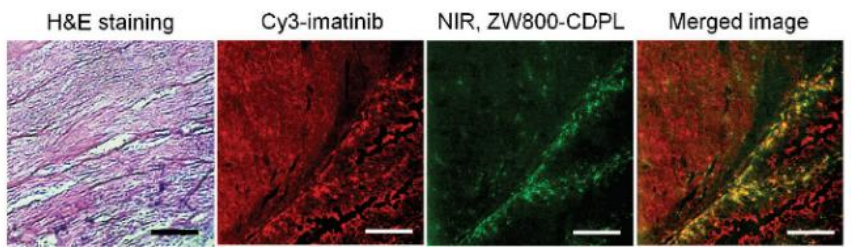

Figure 13. A) In vivo near-infrared fluorescent imaging of the intravenously injected zwitterionic nanocarriers loaded with Cy3-imatinib into xenograft gastrointestinal stromal tumor-bearing mice; the right graph shows the tumor/muscle ratio (TBR) of the nanocarriers for $24 \mathrm{~h}$ post- 
injection. B) Optical and near-infrared fluorescent imaging of various organs (i.e., duodenum (Du), muscle (Mu), liver (Li), kidney (Ki), pancreas $(\mathrm{Pa})$, and tumor $(\mathrm{Tu})) 24 \mathrm{~h}$ post-injection of nanocarriers in xenograft gastrointestinal stromal tumor-bearing mice. Scale bars are $1 \mathrm{~cm} . \mathrm{C}$ ) Optical and near-infrared fluorescent imaging of $\mathrm{Du}, \mathrm{Mu}, \mathrm{Tu}$, intestine (In), and colon (Co) $24 \mathrm{~h}$ post-injection of nanocarriers into genetically engineered gastrointestinal stromal tumorbearing mice. The right graph shows the TBR of the nanocarriers against $\mathrm{Du}$, In, and $\mathrm{Mu}$, respectively. Scale bars are $1 \mathrm{~cm}$. D) Histopathological analysis of tumor site obtained from the genetically engineered gastrointestinal stromal tumor-bearing mice including hematoxylin and eosin (H\&E) staining and near-infrared images of drug (Cy3-labeled imatinib; red color), zwitterionic nanocarriers (lime green color), and their overlaid images. Scale bars are $100 \mu \mathrm{m}$. Printed with permission from Wiley publishing group [79]. 

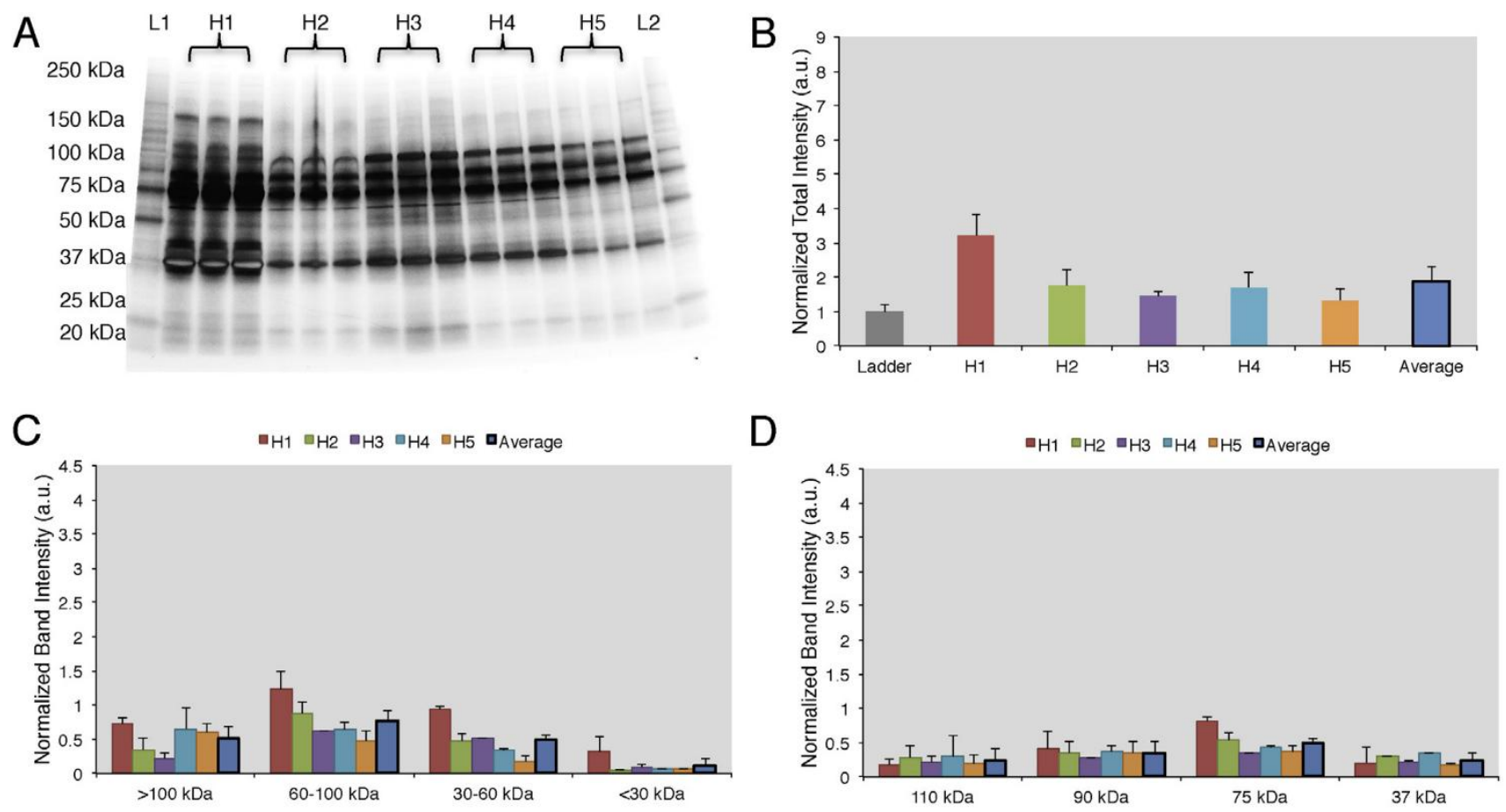

Figure 14. (A) Sodium dodecyl sulfate polyacrylamide gel electrophoresis (SDS-PAGE) image of the corona profiles at the surface of liposomes obtained from incubations of liposomes with human plasma proteins of various healthy donors. (B) Histograms representing the total lane intensity of protein corona profiles of various healthy donors. (C) Histogram of the alterations in band intensity according to proteins' molecular weight. (D) Histogram of the relative densitometry of four major bands. The band intensities were normalized to the ladder intensity. Printed with permission from Elsevier publishing group[105]. 